\title{
LA CIUDAD, SUS GUARDIANES Y LA JUSTICIA \\ UN ESTUDIO DE SU RELACIÓN DURANTE LA VIDA REPUBLICANA \\ DE LA CIUDAD DE MÉXICO (1824-1846)*
}

THE CITY, ITS GUARDIANS AND JUSTICE

A STUDY OF THEIR RELATIONSHIP DURING THE REPUBLICAN LIFE

OF MEXICO CITY (1824-1846)

\author{
Graciela FLORES FLORES \\ El Colegio de México \\ Centro de Estudios Históricos \\ Becaria Posdoctoral \\ graciela_floresf@yahoo.com.mx
}

\section{Resumen}

En 1782 se mandó dividir la ciudad de México en ocho cuarteles mayores y 32 menores con ánimo de facilitar el camino de la justicia. A la par, se crearon distintos personajes para cuidar del orden. El presente artículo tiene por principal finalidad conocer a los agentes de seguridad y vigilancia (auxiliares de cuartel, "guardafaroleros", cabos y vigilantes nocturnos, etcétera) de la ciudad de México, sus funciones y la organización que asumieron para desempeñarlas, además de señalar la estrecha relación que mantuvieron con la justicia durante las dos primeras repúblicas (1824-1846). A través de la cartografía, podremos conocer cómo distribuyeron sus rondas y patrullas para poder dimensionar qué tan efectiva fue su labor al perseguir, aprehender y consignar a los alteradores del orden público ante el juez.

Palabras clave: agentes de seguridad, Ordenanza de 1782, cuarteles mayores, cuarteles menores, jueces.

\begin{abstract}
In 1782 it was ordered to divide Mexico City into eight major barracks and 32 minor barracks in order to facilitate the path of justice. At the same time, different characters were created to take care of the order. The main purpose of this article is to get to know the security and surveillance agents (barracks assistants, "guardafaroleros", corporals and night watchmen, etcetera) of Mexico City, their functions and the organization they assumed to perform them, in addition to note the close relationship they had with justice during the first two republics (1824-1846). Through cartography, we will be able to know how they distributed their rounds and patrols to be able to measure how effective their work was in pursuing, apprehending and consigning the disrupters of public order in front of the judge.
\end{abstract}

Keywords: security agents, Ordinance of 1782, main quarters, minor barracks, judges.

Información del artículo

Recibido: 24 de enero de 2018.

Aceptado: 17 de junio de 2019.

DOI:10.22201/iih.24485004e.2019.57.69978

* unam. Programa de Becas Posdoctorales. Becaria del Instituto de Investigaciones Sociales. Tutor: doctor Hira de Gortari. 


\section{Introducción}

Tras el estertor político que supuso la emancipación novohispana, quedó un enorme reto para los políticos y prohombres del gobierno mexicano: la configuración de un nuevo orden político, jurídico y judicial. Si bien las bases ya se habían colocado años atrás -Cádiz había señalado el camino: la Constitución de Apatzingán respondió a ese impulso-, nada se pudo concretar durante la efímera y convulsa monarquía de Agustín I sino hasta 1823, cuando se concretó el Acta Constitutiva que dio origen a la primera Constitución Federal en 1824. La norma constitucional señaló entonces la senda: una división tripartita de poderes.

El Poder Judicial, según el artículo 123 de la Carta Magna, residiría en una Corte Suprema de Justicia, juzgados de Distrito y Tribunales de Circuito a nivel federal, mientras que, en el ámbito estatal, según el Acta Constitutiva, la justicia recaería en los tribunales (arts. 18 y 23). En cuanto a la justicia ordinaria, el Tribunal Superior se ocuparía de la revisión de sentencias en segunda y tercera instancias, en tanto que los juzgados de letras se encargarían de la primera instancia judicial. Por su parte los alcaldes constitucionales, que pertenecían al Ayuntamiento de la ciudad, fungirían como jueces, aunque no tuvieran formación en derecho, ocupándose de la justicia inmediata, de carácter "doméstico", a través de trámites amistosos o de común acuerdo entre las partes, conocidos como "conciliaciones" y "juicios verbales".

A excepción de los negocios judiciales iniciados por querella de parte en primera instancia y de los realizados por los alcaldes constitucionales, el aparato judicial comenzó a funcionar cuando hubo delito que perseguir (o algún pleito a dirimir), por lo que, custodiados lo mejor posible por auxiliares de cuartel, oficiales auxiliares, cabos, guardafaroleros, vigilantes y demás agentes de seguridad y orden, llegaban diariamente al juzgado carcelario todo tipo de alteradores del orden público, algunos por asuntos que habían terminado en golpizas y heridas, robo de enseres de poca cuantía hasta los que implicaban "escalación" u horadación de muro, "fractura" de puertas o uso de ganzúas y montos considerables, así como los de índole sexual (estupro, violaciones, prostitución, "incontinencia”, sodomía, bestialidad [zoofilia] y lenocinio, entre otras variantes).

La historiografía que ha centrado su atención en los elementos de seguridad antes mencionados lo ha hecho con la finalidad de conocer la conformación de la policía en sentido moderno, esto es, abocada a las funciones 
de orden y seguridad de la ciudad de forma exclusiva, desde la vertiente institucional ${ }^{1}$ o bien en la lingüística y conceptual; ${ }^{2}$ en ambos casos ya desprendida del concepto de "policía" vigente en el Antiguo Régimen, que era más amplio por cuanto comprendía el buen gobierno de las ciudades, o en palabras de Nacif Mina, eran "las acciones administrativas, controladas por el Ayuntamiento de México, y utilizadas para la vigilancia del cumplimiento de los bandos públicos y órdenes en la ciudad, con la intención de que los servicios públicos fueran para el bien común".3

Uno de los estudios que se centra en los auxiliares de cuartel, sin pretender encontrar la raíz de la policía moderna, es el de José Antonio Serrano Ortega, "Los virreyes del barrio: alcaldes auxiliares y seguridad pública, 1820-1840", ${ }^{4}$ en el que aborda diversas e interesantes esferas relativas a la administración de seguridad en la ciudad, como las controversias entre los ediles del ayuntamiento y las "autoridades superiores", el control social y las demandas de justicia en medio de las agitaciones políticas y sociales que hacían clamar por mejores aparatos de vigilancia y en el que aborda la relación de los auxiliares con la justicia, aunque no como tema principal.

El presente estudio, por tanto, pretende servir como un acercamiento a la forma de proceder de los cuerpos y agentes de seguridad capitalinos y su relación con la justicia durante el periodo que abarca dos experimentos republicanos, de 1824 a 1846, para conocer cómo es que procedían y cómo se distribuyeron en la ciudad y poder determinar qué tan eficaz pudo haber

${ }^{1}$ Algunos autores son Jorge Nacif Mina, "Policía y seguridad pública en la ciudad de México, 1770-1848”, en Regina Hernández Franyuti (comp.), La ciudad de México en la primera mitad del siglo XIX, 2 v., México, Instituto de Investigaciones Dr. José María Luis Mora, 1994, v. II, p. 9-50, y José Antonio Yáñez Romero, Policía mexicana: cultura política, (in)seguridad y orden público en el gobierno del Distrito Federal, 1821-1876, México, Universidad Autónoma Metropolitana/Plaza y Valdés, 1999.

${ }^{2}$ Regina Hernández Franyuti, "Historia y significados de la palabra policía en el quehacer político de la ciudad de México. Siglos XVI-XIX”, Ulúa. Revista de historia, sociedad y cultura, n. 5, 2005, p. 9-34, y Diego Pulido Esteva, "Policía: del buen gobierno a la seguridad, 1750-1850", Historia Mexicana, n. 3, enero-marzo 2011, p. 1595-1642, respectivamente.

${ }^{3}$ Nacif Mina, "Policía y seguridad pública en la ciudad de México, 1770-1848”, p. 11. Para conocer las implicaciones de policía en sentido extenso, tal como se entendía a finales del Siglo de las Luces, véase el estudio de Hira de Gortari Rabiela, "La ciudad de México de finales del siglo XVIII: un diagnóstico de la 'ciencia de policía' ”, Historia Contemporánea, n. 24, 2002, p. 115-135.

${ }^{4}$ Juan Antonio Serrano Ortega, "Los virreyes del barrio: alcaldes auxiliares y seguridad pública, 1820-1840”, en Carlos Illades y Ariel Rodríguez Kuri (eds.), Instituciones y ciudad. Ocho estudios históricos sobre la ciudad de México, México, Sociedad Nacional de Estudios Regionales/Uníos, 2000, p. 21-60. 
sido su actuación, pues de ella dependía, en buena medida el funcionamiento de la maquinaria judicial (juzgados y cárceles).

Un primer acercamiento será a través de la cartografía elaborada con base en documentación oficial, ${ }^{5}$ principalmente reglamentos y nombramientos en los que se mencionan datos como el número de individuos por zonas y algunos domicilios (cuando menos calles) que fue posible cartografiar; quizás al comparar lo que sugieren los planos con la práctica, se pueda llegar a responder sobre la eficacia de éstos para detener y conducir reos a los juzgados. Por supuesto, llegado el momento, haré un alto en el juzgado, para conocer el proceso que los reos experimentaron luego de la detención.

\section{La ciudad de México y su división por cuarteles}

El 18 de noviembre de 1824 el Congreso federal emitió el decreto que daba a conocer la creación del Distrito Federal, sede de los poderes políticos, cuya extensión comprendió dos leguas (aproximadamente nueve kilómetros) de radio a partir de la Plaza Mayor. El territorio del Distrito Federal

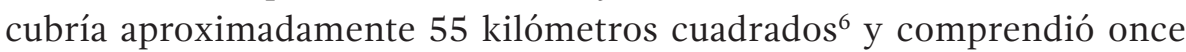
municipalidades: México, Guadalupe Hidalgo, Tacubaya, Azcapotzalco, Tacuba, Iztacalco, Mixcoac, Iztapalapa, Popotla, La Ladrillera, Nativitas, Mexicalzingo; dos ciudades, dos villas, 32 pueblos, 85 barrios, 16 haciendas, 22 ranchos, dos molinos, un fuerte y dos huertas. ${ }^{7}$ La capital seguiría siendo, tal como durante el periodo novohispano, la Ciudad de México, y continuó

${ }^{5}$ Agradezco la valiosa colaboración del geógrafo José Marcos Osnaya Santillán, quien trazó los planos que se presentan en este estudio con base en los datos y la información recopilados para la presente investigación. El plano base está georreferenciado y se trazó a partir del de Diego García Conde, Plano general de la Ciudad de México. Levantado por el Teniente Coronel Don [...] en el año de 1793. Aumentado y corregido en lo más notable por el Teniente Coronel retirado, Don Rafael María Calvo en el de 1830, que custodia la Mapoteca Manuel Orozco y Berra. La división de la capital en cuarteles mayores, menores, secciones y manzanas para la primera mitad del siglo XIX se trazó a partir de Archivo Histórico del Distrito Federal (en adelante, AHDF), Demarcaciones: Cuarteles, v. 650, exps. 5 y 8, años 1830 y 1846 , respectivamente.

${ }^{6}$ José Luis Vázquez Alfaro, Distrito Federal. Historia de las instituciones jurídicas, México, Universidad Nacional Autónoma de México, Instituto de Investigaciones Jurídicas/Senado de la República, 2010, p. 10.

${ }^{7}$ Regina Hernández Franyuti, El Distrito Federal: historia y vicisitudes de una invención, 1824-1994, México, Instituto de Investigaciones Dr. José María Luis Mora, 2008 (Historia Urbana y Regional), p. 44. 
siéndolo durante las siguientes administraciones políticas, ${ }^{8}$ e incluso mantuvo la estructura organizativa que le había heredado la Ordenanza de 1782 al dividirla en 8 cuarteles mayores y 32 menores; es decir, cada uno de los mayores quedó conformado por cuatro menores y tal división obedeció a la observancia del orden y la justicia en la capital. Las razones de la Ordenanza se expresaron así:

La dilatada extensión de esta Ciudad: la irregular disposición de sus barrios y arrabales, y la situación de las habitaciones de éstos, que los hace imposibles al registro, y en muchos de ellos aun al tránsito; y su numerosísimo vecindario, especialmente de la Pleve [sic], han dificultado en todos tiempos, que el corto número de Señores Ministros de la Real Sala del Crimen, y Jueces Ordinarios, pueda llevar su vigilancia a todas partes, y mucho menos visitarlas con Rondas nocturnas. ${ }^{9}$

Es decir, el crecimiento de la urbe y la falta de orden dificultaban la adecuada vigilancia y el alcance de la justicia, por lo que se tomaron previsiones para subsanar deficiencias y atender dichas necesidades. Si bien la Ordenanza de 1782 no fue la única en la materia, sí fue la que mayor impacto, utilidad y vigencia tuvo, pues la Ciudad de México siguió utilizando tal estructura organizativa hasta principios del siglo xx. Anteriormente hubo varios intentos por dividir la capital en cuarteles para su mejor control, según la misma Ordenanza, los hubo en 1713, 1720 y 1750, ${ }^{10}$ cada cuartel quedaría bajo resguardo de los "señores alcaldes", corregidores y alcaldes ordinarios, o bien de los Ministros de vara y ronda, o bien de "Comisarios y Quadrilleros". ${ }^{11}$ Sin embargo, cada proyecto enfrentó dificultades que impidieron su puesta en marcha, siendo el 4 de diciembre de 1782 cuando

${ }^{8}$ Sobre la controversia para mantener o cambiar la ciudad de México como capital, véase Vázquez Alfaro, Distrito Federal. Historia de las instituciones jurídicas, p. 4-6.

9 AHDF, Ordenanzas y Otros Documentos, 1736-1836, v. 2984, exp. 23, f. 1.

${ }^{10}$ Otra medida de la que da cuenta la Ordenanza de 1782 ocurrió en 1744, cuando se le propuso al rey que para hacer eficiente el ejercicio de la justicia, se asignaran algunas pocas iglesias para que los delincuentes gozaran de inmunidad y que fueran las más alejadas del comercio. Dicha medida fue la única donde no se mencionó una nueva división de la ciudad. AHDF, Ordenanzas y Otros Documentos, 1736-1836, v. 2984, exp. 23, f. 2 y 3.

${ }^{11}$ En 1778 hubo otro intento por mantener el orden y la justicia en la ciudad. Por real orden se dispuso que "los Alcaldes de Corte y los Ordinarios vivan precisamente en sus respectivos cuarteles, y visiten con frecuencia las Pulquerías, practicando quantos juiciosos arbitrios les dicte su zelo, para evitar en ellas las embriagueces y demás desórdenes”, medida que quedó sin efecto al morir el virrey Bucareli. AHDF, Ayuntamiento, Ordenanzas y Otros Documentos, 1736-1836, v. 2984, exp. 23, f. 4 y 5. 
se aprobó, al fin, la división en cuarteles semejantes a los madrileños, incluyendo la figura representativa del orden: el alcalde de barrio, ${ }^{12}$ que por entonces, según voces enteradas, estaba dando muy buenos resultados; el responsable para tamaña empresa en la capital de Nueva España fue el oidor Baltasar Ladrón de Guevara. ${ }^{13}$

La implementación de los alcaldes de barrio fue toda una innovación en materia de orden y control social, pues anteriormente, las funciones de aprehender reos para ponerlos a resguardo carcelario y luego ante la presencia del juez, había sido una función exclusiva de los alcaldes ordinarios de la ciudad, el corregidor y los alcaldes del crimen de la Real Audiencia. Posteriormente, también comenzó a operar el Tribunal de la Acordada que persiguió y juzgó delitos contra la propiedad, personas y bebidas prohibidas y que, de hecho, contaba con su propia cárcel. Sin embargo, sus funciones se vieron rebasadas ante el crecimiento de la ciudad y los crímenes, por lo que la adopción de los alcaldes de barrio que además poseían fuero judicial fue muy conveniente para asegurar un mayor alcance de la justicia, mantener el orden entre los vecinos y sus propiedades y así conseguir "saludables efectos tanto en la administración de justicia como en el gobierno político". ${ }^{14}$

Al llegar a la vida independiente y al extinguirse las instancias judiciales de Antiguo Régimen, el enorme vacío que pudo suponer la ausencia de aquellos agentes fue cubierto por los "auxiliares de cuartel" y algunos nuevos cuerpos de seguridad que surgieron como iniciativa del Ayuntamiento o bien del gobernador o el prefecto del Distrito durante el federalismo o el centralismo, y que aprovecharon la división por cuarteles de 1782, que permaneció vigente apenas con una pequeña modificación en 1846.

${ }^{12}$ En Madrid, luego de la conmoción social generada por los motines y revueltas de la primavera y el verano del año de 1766, como el "motín contra Esquilache", las autoridades contemplaron la reforma del orden y control de la ciudad: su división en ocho cuarteles mayores y 64 menores o barrios (por real cédula de Carlos III, el 6 de octubre de 1768) y en cada uno de los mayores, un alcalde de barrio. Véase Brigitte Marin, "Los alcaldes de barrio en Madrid y otras ciudades de España en el siglo XviII: funciones de policía y territoriales", Antropología. Boletín oficial del Instituto Nacional de Antropología e Historia, n. 94, 2012, p. 1931, p. 21, y Arnaud Exbalin Oberto, "Los alcaldes de barrio. Panorama de los agentes del orden público en la ciudad de México a finales del siglo xviII", Antropología. Boletín Oficial del Instituto Nacional de Antropología e Historia, México, n. 94, 2012, p. 49-59, p. 50.

${ }^{13}$ Por supuesto, tales medidas, de uno y otro lado del Atlántico, obedecieron a las discusiones en Europa sobre un nuevo modelo de policía y su mejora, sobre todo en el último tercio del siglo XVIII, un movimiento de reformas muy amplio en las capitales y grandes ciudades.

${ }^{14}$ AHDF, Ordenanzas y Otros Documentos, 1736-1836, v. 2984, exp. 23, f. 2, 4 y 5. 
En el plano 1 se puede ver la división que estuvo vigente durante la primera república federal y durante casi todo el centralismo, mientras que en el plano 2 son visibles las demarcaciones definidas en 1846 al final del centralismo para el cuartel mayor $8 .{ }^{15}$

De la ciudad y sus guardianes

En 1842 la ciudad de México contaba con una población menor a los 120000 habitantes, pues entre los últimos años del siglo xvin y hasta mediados del siglo xix el espacio urbano no tuvo un crecimiento social importante, ${ }^{16}$ debido a que "las condiciones económicas y la serie de patologías biosociales limitaron el crecimiento natural de la urbe, pues sus habitantes enfrentaron un número importante de epidemias que incidieron negativamente sobre el tamaño de la población de la ciudad". ${ }^{17}$

Aunque la población no creció de forma importante, sí poseyó características que la hacían atractiva a propios y extraños: no sólo era la sede de los poderes federales y, más tarde, del centralismo; también se mantuvo como el innegable centro espiritual, comercial y financiero de la República, a la vez que fungía como faro para las mentes más brillantes - que acudían a formarse a los mejores institutos, liceos, colegios... a la universidad-. Asimismo, fue la ciudad de las grandes imprentas que abastecían la demanda de textos académicos y literarios, además de capital del entretenimiento no sólo por sus teatros y plazas de toros, sino por los lugarejos que servían como puntos de encuentro y solaz a las distintas clases sociales en sus muchas tabernas, pulquerías y hasta billares.

A la par de su innegable oropel, había una parte de la ciudad que no era lustrosa ni digna de orgullo. Hacia la primera mitad del siglo xıx, a la capital la describían como sucia, caótica y hasta peligrosa, escenario de crímenes atroces y delitos de poca monta, paraíso de ladronzuelos, parias y prostitutas, vagos y mal entretenidos. Los contrastes de la urbe, su peligrosidad y la necesidad de mantenerla pacífica condujeron a su división en cuarteles

${ }^{15}$ AHDF, Demarcaciones: Cuarteles, v. 650, exp. 8.

${ }^{16}$ Sonia Pérez Toledo, Población y estructura social en la ciudad de México, 1790-1842, México, Universidad Autónoma Metropolitana-Iztapalapa, 2004, p. 123.

${ }^{17}$ Idem. Sobre el impacto de las epidemias o patologías "biosociales" en la población de México durante los siglos XVI al XX, véase Elsa Malvido, La población, siglos XVI al XX, México, Universidad Nacional Autónoma de México/Océano, 2006. 


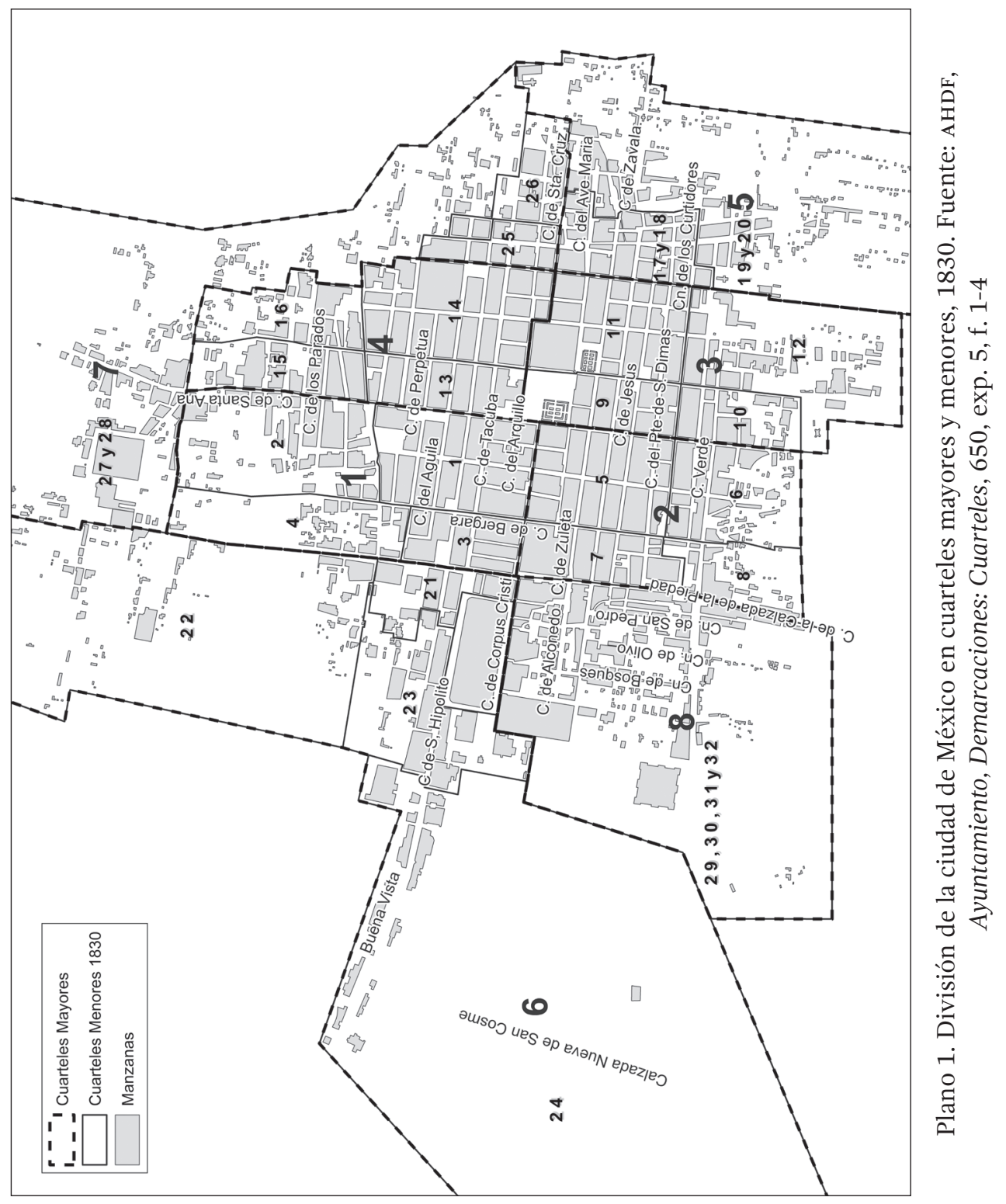




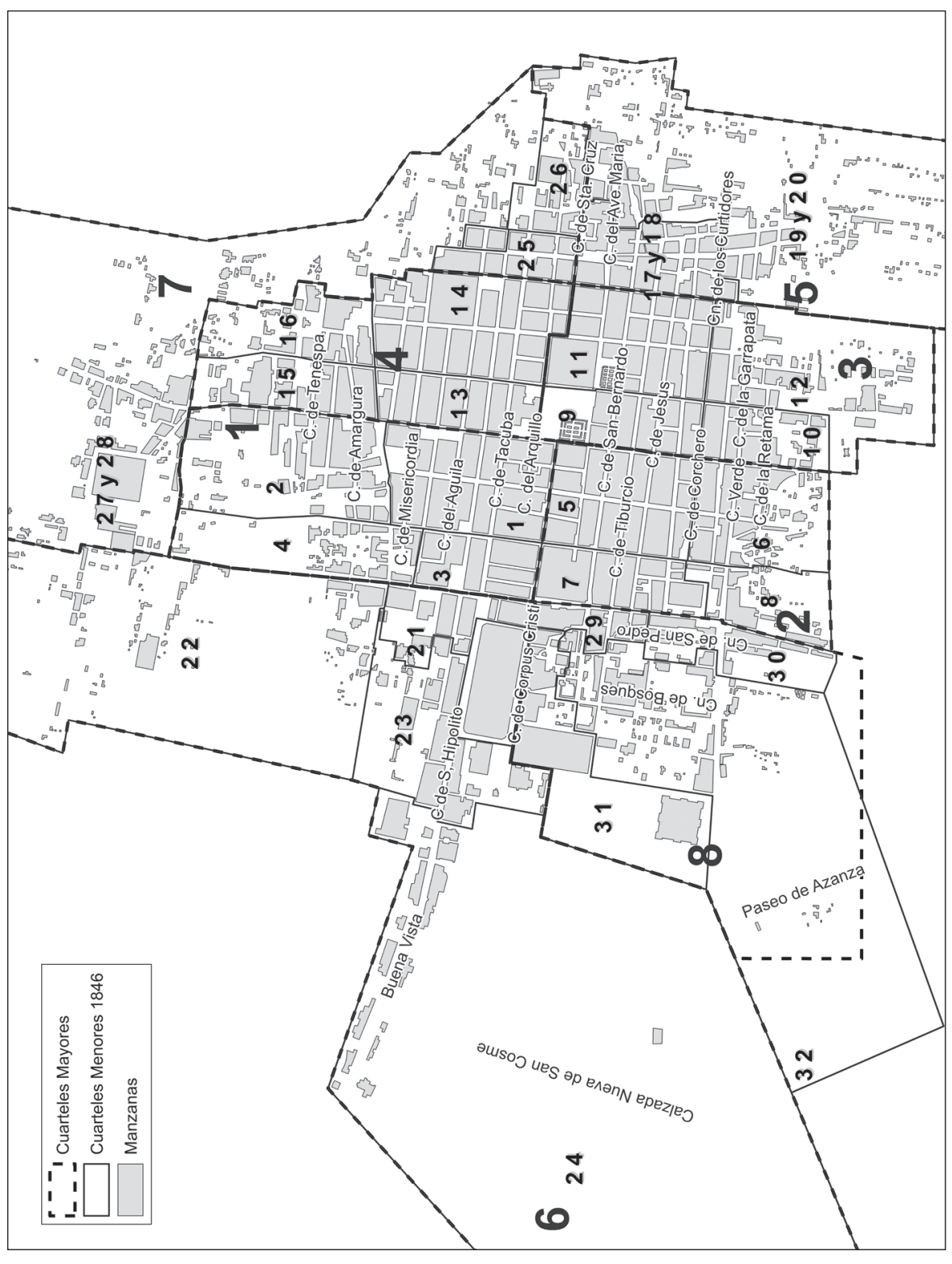

ป⿱艹 
mayores y menores, y a la creación de cuerpos y agentes de vigilancia. Durante el periodo que me ocupa hubo varios de ellos.

Algunos databan de las últimas décadas del virreinato; otros, se habían generado según los pareceres y necesidades de las administraciones políticas, ya federalistas o centralistas. Algunos obedecían al Ayuntamiento, otros al gobernador del distrito o al prefecto; aunque sin importar su signo o forma, ni filiación política, la consigna fue única: vigilar para prevenir y disuadir las conductas peligrosas y/o criminales. Por supuesto, a los agentes y cuerpos de vigilancia competía poner a disposición del juez de turno de la cárcel de la Diputación (principalmente) o la Nacional a aquellos detenidos que osaban alterar el orden público o que simplemente fueran sospechosos; correspondía al juez determinar la sanción a la que se harían acreedores.

Dentro de los cuerpos y agentes de seguridad vigentes en la época republicana, y cuyos antecedentes se remontan a las últimas décadas del virreinato, figuran los alcaldes auxiliares de cuartel, cuyo reglamento se publicó el 7 de febrero de 1822, en plena administración de Iturbide. Su actividad fue más que evidente a lo largo de las dos administraciones políticas que sucedieron a la breve monarquía mexicana, equiparables a los "alcaldes de barrio" cuyas funciones principales, al gozar de jurisdicción criminal, según la Ordenanza de 1782, consistieron en administrar justicia, prevenir y castigar los delitos, recabar las pruebas en delitos graves e integrar la sumaria para el juez. ${ }^{18}$

Al ser nombrados por el virrey, no podían excusarse del cargo (pese a ser concejil y no percibir sueldo alguno), so pena de ser multado y hasta desterrado. Los alcaldes debían vivir en el cuartel a su encargo y portarían un uniforme. ${ }^{19}$ Aunque se desconoce cuándo salieron del escenario judicial, hay indicios de su actuación hacia $1815-1816 .{ }^{20}$ No fue hasta la consumación de la Independencia, y plenamente en la vida republicana, cuando los alcaldes auxiliares de cuartel tomaron la escena callejera para hacerse cargo de la seguridad, la vigilancia y el orden.

${ }^{18}$ AHDF, Ayuntamiento, Ordenanzas y Otros Documentos, 1736-1836, v. 2984, exp. 23, f. 28. El subrayado es mío.

${ }^{19}$ El uniforme consistía en "casaca y calzón azul, vuelta de manga encarnada, y en medio de ella, a lo largo, un alamar de plata: llevarán bastón, como insignia de la Real Justicia...”. Ibidem, p. 26.

${ }^{20}$ Yáñez Romero, Policía mexicana: cultura política..., p. 85-87. 
Según el "Reglamento de los alcaldes auxiliares...", ${ }^{21}$ éstos debían ser designados por el "regidor del cuartel" y el ayuntamiento los nombraría dando a conocer al público sus nombres y domicilios para que los ciudadanos supieran a quién recurrir en caso de necesidad, ya para demandar auxilio, presentar quejas o denunciar la inobservancia de los bandos de policía, pues tuvieron una doble función: vigilar el orden y garantizar el cumplimiento de los bandos de policía (limpieza de la ciudad, iluminación, que no se vendiera comida en lugares prohibidos, etcétera).

Los regidores eran electos cada dos años y tenían a su encargo dos cuarteles menores cada uno pero, a diferencia de los auxiliares, no estaban obligados a vivir en los cuarteles a su encargo, lo que es visible en el plano 3 , por ejemplo, en 1824 el regidor de los cuarteles 1 y 2 habitaba en el cuartel menor 14 del mayor 4, o el regidor de los cuarteles 11 y 12 habitaba en el cuartel menor 22 perteneciente al mayor número 6. Fueron pocos los casos en que el domicilio del regidor coincidía con el de los cuarteles a su cargo, como el de los cuarteles menores 9 y 10, que sí tenía su morada en el menor 10 del mayor 3. En ambos casos, y al igual que los ya extintos alcaldes de barrio, sus cargos eran honoríficos y estaban sujetos a sanciones si declinaban tomar posesión de ellos.

Dentro de los cuerpos de seguridad, otros que poseyeron larga tradición fueron los "celadores públicos". Instituidos el 28 de mayo de $1826^{22}$ y más tarde complementados con el Reglamento del 29 de diciembre de 1829,23 sustituyeron al virreinal "alumbrado de las calles de Méjico" (cuyo reglamento propio, del 6 de abril de 1790, fue mandado elaborar por el virrey conde de Revillagigedo, a sólo ocho años de que se estableciera la nueva

21 "Reglamento de alcaldes auxiliares para la seguridad de las personas y bienes de los vecinos de esta capital, y la observancia de las leyes de policía”, en Juan Rodríguez de San Miguel, Pandectas hispano-megicanas, o sea, Código general comprensivo de las leyes generales, útiles y vivas de las Siete Partidas, recopilación novísima, la de Indias, autos y providencias conocidas por de Montemayor y Belaña, y cédulas posteriores hasta el año de 1820: con exclusión de las totalmente inútiles, de las repetidas, y de las expresamente derogadas, 3 v., México, Impreso en la Oficina de Mariano Galván Rivera, 1839, v. I, p. 677-679.

22 "Se establece en el Distrito un cuerpo de policía municipal bajo el título de celadores públicos”, 28 de mayo de 1826, en Juan Rodríguez de San Miguel, Manual de providencias económico-políticas para uso de los habitantes del Distrito Federal, México, Imprenta de Galván a cargo de Mariano Arévalo, 1834, p. 146-147.

23 "Reglamento para el alumbrado de Méjico", 29 de diciembre de 1829, en Rodríguez de San Miguel, Manual de providencias económico-políticas..., p. 147-149. 
división de la ciudad de México). ${ }^{24} \mathrm{El}$ "alumbrado" novohispano cumplía una función vital: mantener iluminada la capital en las noches, gracias a doce farolas a cargo de cada "guardafarolero" con los enseres para su labor (que consistían en chuzos, aceite y mechas) que debían solicitar a su jefe inmediato, el "guarda mayor de alumbrado". Posteriormente, luego de una adición al reglamento del alumbrado ${ }^{25}$ se crearon ocho plazas que constituyeron el "brazo armado" de los guardas, pues además de llevar farol, cargaban un sable. Así de bárbaras parecían las calles de la ciudad.

Finalmente, en 1829 se suprimieron las ocho plazas de cabos creadas por Revillagigedo y se instituyeron los "guarda serenos" que eran también ocho y provenían de la compañía de caballería de celadores públicos, instaurándose, de hecho, una estructura mucho más compleja. En la cúspide de la pirámide organizacional se encontraba el gobernador del distrito, seguido del jefe superior de celadores públicos, un cabo primero de alumbrado y en la base de la estructura los cabos de alumbrado. Los guardafaroles realizaban rondas y patrullas. Para ejercer su labor, acudían al cuartel de seguridad pública por aceite y mechas para proveer los faroles y también se aseguraban de mantenerlos limpios.

Cuando menos estos dos cuerpos de seguridad y vigilancia se mantuvieron activos durante el federalismo y el centralismo; mientras que, a la par, en cada administración política se crearon otros más, lo que de entrada denota la insuficiencia de aquéllos o bien la cada vez más demandante necesidad de orden y control social. ${ }^{26}$ Desde su creación y en la vida republicana, el alumbrado de las calles de México tuvo por encargo "aprehender

24 "Reglamento formado de orden del exmo. sr. virrey conde de Revillagigedo, para el gobierno que ha de observarse en el alumbrado de las calles de Mégico”, en Rodríguez de San Miguel, Pandectas hispano-megicanas..., v. I, p. 683.

25 “Adición al reglamento del alumbrado", en Rodríguez de San Miguel, Pandectas hispano-megicanas..., v. I, p. 684.

${ }^{26}$ Durante el primer federalismo también se instituyeron los "vigilantes del orden público", cuyo reglamento data del 20 de diciembre de 1828 y si bien sus funciones y modus operandi fue semejante al de los auxiliares de cuartel, no me ocuparé de ellos por no haber más referencia a su presencia que dicho reglamento; tales vigilantes pudieron haber sido creados debido a los disturbios ocasionados durante el llamado "Motín de la Acordada" y que condujo al saqueo del mercado de El Parián el 4 de diciembre de 1828. Sobre las referencias a los vigilantes del orden público, consúltese Yáñez Romero, Policía mexicana: cultura política..., p. 108 y 258, 259. El reglamento íntegro puede consultarse en Basilio José Arrillaga, Recopilación de leyes, decretos, bandos, reglamentos, circulares y providencias de los supremos poderes y otras autoridades de la República Mexicana formada por orden del supremo Gobierno, México, Imprenta de J. M. Fernández de Lara, calle de la Palma núm. 4, 1838, p. 178-182. 
a los malhechores o ladrones que encontrasen, depositándolos en la guardia, cuartel o cárcel más inmediata, dando parte al guarda mayor o su teniente cuando pase la ronda". ${ }^{27}$

Según su Reglamento, expedido en 1829, sus funciones de vigilancia comenzaban al encenderse las farolas, recorrían la ciudad e informaban a sus superiores sobre todos los pormenores de sus rondas; sus funciones también consistieron en aprehender a ladrones, ebrios, y a cuanto facineroso encontrasen, "depositándolos en el vivac más inmediato o en la cárcel de la Diputación”. ${ }^{28}$

Posteriormente, el 4 de febrero de 1834, durante el federalismo, se creó el llamado "oficial auxiliar de policía" que dependió del ayuntamiento de la capital y que no debe confundirse con los alcaldes auxiliares de cuartel, pues a diferencia de éstos se les dio una encomienda muy puntual: auxiliar "en todas sus providencias" a los capitulares del ayuntamiento y jueces de letras, ${ }^{29}$ constituyéndose en una especie de "policía judicial", aunque al igual que aquéllos, daban cuenta de los pormenores de sus rondas a los regidores de su cuartel. Por su utilidad, dicha figura se mantuvo vigente durante el centralismo. ${ }^{30}$

Un poco más adelante, en 1838 la Junta Departamental creó su propio "cuerpo de policía municipal" integrado por vigilantes nocturnos ${ }^{31}$ y diurnos, ${ }^{32}$ cuya designación correspondió al prefecto de la capital (con la apro-

27 "Reglamento formado de orden del exmo. sr. virrey conde de Revillagigedo, para el gobierno que ha de observarse en el alumbrado de las calles de Mégico", en Rodríguez de San Miguel, Pandectas hispano-megicanas..., v. III, p. 683.

28 "Reglamento para el alumbrado de México", del 20 de diciembre de 1829, en Rodríguez de San Miguel, Manual de providencias económico-políticas..., p. 685.

${ }^{29}$ AHDF, Bandos, Leyes y Decretos, caja 6, exp. 48, "José María Tornel, gobernador del Distrito Federal. Se nombrará un oficial auxiliar de policía en cada manzana, por los regidores encargados de los cuarteles en que está dividida la Ciudad para evitar la inseguridad que se vive en ésta", 4 de febrero de 1834, art. 1.

${ }^{30}$ AHDF, Bandos, Leyes y Decretos, caja 11, exp. 37, "El ciudadano Francisco Ortiz de Zárate, ayudante general de la Plana mayor del ejército, General de brigada graduado y Gobernador interino del Departamento de México. Reglas para los oficiales de policía distribuidos en las manzanas de la capital", 22 de septiembre de 1841.

31 "Reglamento del cuerpo de policía municipal de vigilantes nocturnos", 7 de abril de 1838, en Manuel Dublán y José María Lozano, Legislación mexicana o colección completa de las disposiciones legislativas expedidas desde la independencia de la República ordenada por los licenciados Manuel Dublán y José María Lozano, México, Imprenta del Comercio, a cargo de Dublán y Lozano, Hijos, Calle de Cordobanes, número 8, 1876, t. III, p. 470-474.

${ }^{32}$ AHDF, Bandos, Leyes y Decretos, caja 9, exp. 60, "El ciudadano Luis Gonzaga Vieyra, Coronel retirado, y Gobernador constitucional del Departamento de México. Reglamento para los vigilantes diurnos”, 7 de abril de 1838 . 
bación del gobernador). También se trató de una organización compleja y jerarquizada: los vigilantes dependían de cabos y todos, a su vez, rendían cuentas al gobernador.

Igualmente, durante el centralismo el 26 de septiembre de 1845 se creó la "fuerza de policía": ${ }^{33}$ un cuerpo de organización compleja, jerarquizada y mixta; algunos montaban a caballo, otros eran "de a pie" y sus hombres podían poseer o no fuero militar. Los primeros obedecían a un jefe de policía, un teniente de policía y a cuatro comisarios; mientras que los segundos, a tres subalternos de policía. Todos estaban sujetos al gobernador del departamento de México. Hasta aquí esbozamos las figuras de algunos cuerpos y agentes de la seguridad y vigilancia creadas hasta en tres momentos políticos distintos, algunas con raíces novohispanas y hasta de tradición madrileña, y otras surgidas en la administración federal o central. Ahora veamos con detenimiento únicamente los cuerpos de vigilantes más nutridos y con más presencia en la ciudad; a través de la cartografía, será posible aproximarnos a su organización y distribución para efectuar sus rondas y patrullas.

Atajar delitos y delincuentes: auxiliares de cuartel

Para el periodo de estudio que nos ocupa no hay un cuerpo único encargado de la vigilancia sino varios; algunos cuerpos usaban uniforme, otros no; algunos eran asalariados y en otros casos el cargo era honorífico; había quienes contaban con fuero militar y otros más empleaban civiles para hacer rondas. Tal disparidad (y variedad) puede explicarse, como bien estudia Serrano Ortega, en una necesidad urgente de vigilancia y orden, y en la disputa entre los ediles del ayuntamiento y el gobernador del Distrito, durante el federalismo, o el prefecto de distrito, durante el centralismo, quienes aportaron sus mejores argumentos jurídicos para ocuparse de la vigilancia y la seguridad de la capital, un territorio que se convirtió en escenario de discordias entre ambos. No obstante, abanderaron una clara consigna: velar por la seguridad de los bienes de los ciudadanos. Ello implicó aprehender o perseguir a los que osaran transgredir aquel sagrado mandato.

${ }^{33}$ AHDF, Bandos, Leyes y Decretos, caja 15, exp. 3, "Mucio Barquera, presidente de la Asamblea de México y gobernador interino de su departamento. Decreto y reglamento para el cuerpo de policía", 26 de septiembre, 1845. 
Los auxiliares de cuartel se distinguieron por tener presencia en toda la ciudad; como se recordará, se designaron dos por cada cuartel menor: así que, si existían 32 cuarteles menores, hubo entonces 64 auxiliares; ellos debían rendir cuenta a su respectivo regidor de cuartel, a la sazón, 16 de ellos, cada uno con la obligación de ocuparse de dos cuarteles menores. En el plano 3, perteneciente a la distribución de los regentes y auxiliares para 1824, se puede apreciar que guardaron una distribución equitativa y que cubrían prácticamente toda la ciudad, ${ }^{34}$ y no sólo eso, cada auxiliar contó con el apoyo de seis vecinos; precisamente por ello, el Reglamento exigió que tanto unos como otros fueran de "reconocida probidad, honradez y buen nombre". ${ }^{35}$

En un libro que pagaba el ayuntamiento debían llevar un control escrupuloso de los vecinos, anotando de cada casa de su medio cuartel el número de personas que en ella vivían, sus edades y ocupaciones; también la información relativa a cada taller, almacén, vinatería y fonda; además del movimiento de inquilinos de los mesones (los que llegaban y los que partían).

Según el Reglamento y según el plano elaborado a partir de los domicilios de cada uno de ellos, su distribución los hizo idóneos para "evitar todo desorden e infracción de las leyes de policía y buen gobierno", ${ }^{36}$ lo que implicó dar noticia a su respectivo regidor del estado del aseo, el alumbrado y el empedrado de las calles, cuidar que en su territorio no hubiera vagos ni gente mal entretenida, casas de prostitución o borrachos tirados en las calles $^{37}$ y que no se practicaran "juegos prohibidos".

Aunado a dichas labores, también desempeñaron otras más dinámicas y no exentas de riesgo: capturar in fraganti o cuando se temiera la fuga de algún reo, en cuyo caso debían presentarlo al alcalde constitucional para conducirlo a la cárcel de la Diputación o de la Ciudad, y en menor medida a la Nacional de Palacio y, después de 1831, a la de la ex Acordada, nueva sede de la cárcel nacional (véase plano 4). Sin embargo, al calor de

${ }^{34}$ El plano se construyó a partir de los domicilios de los regidores y auxiliares que el Ayuntamiento mandó hacer de conocimiento público, AHDF, Auxiliares, v. 389, exp. 16, “Auxiliares. Nombramiento de los que funcionan este año”, 1824.

35 "Reglamento de alcaldes auxiliares para la seguridad de las personas y bienes de los vecinos de esta capital, y la observancia de las leyes de policía”, en Rodríguez de San Miguel, Pandectas hispano-megicanas..., v. I, p. 677.

36 "Reglamento de alcaldes auxiliares para la seguridad de las personas y bienes de los vecinos de esta capital, y la observancia de las leyes de policía”, art. 28, en Rodríguez de San Miguel, Pandectas hispano-megicanas..., v. I, p. 677.

${ }^{37}$ AHDF, v. 390, “Cartilla para los auxiliares y ayudantes de cuartel”, art. 9. 


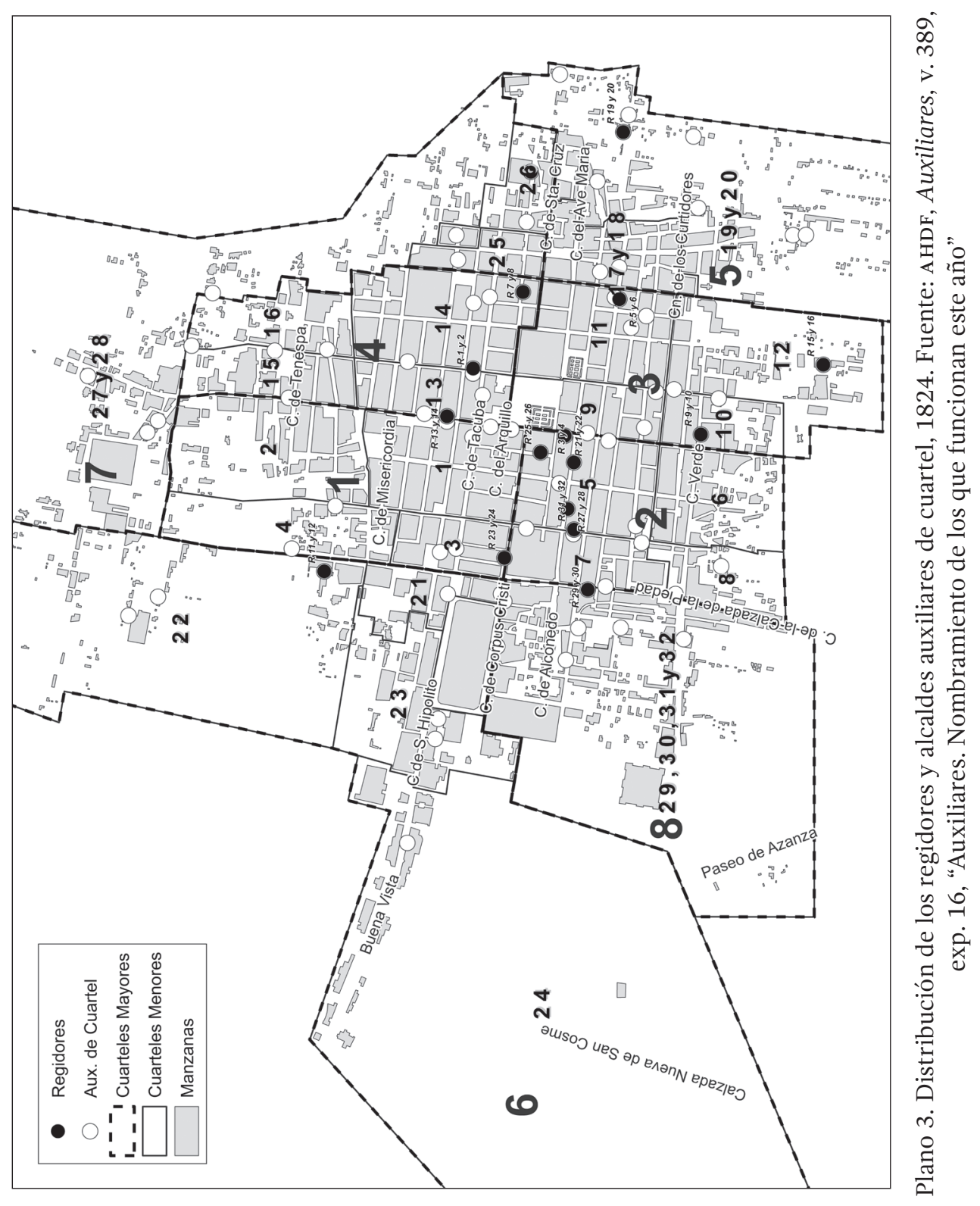




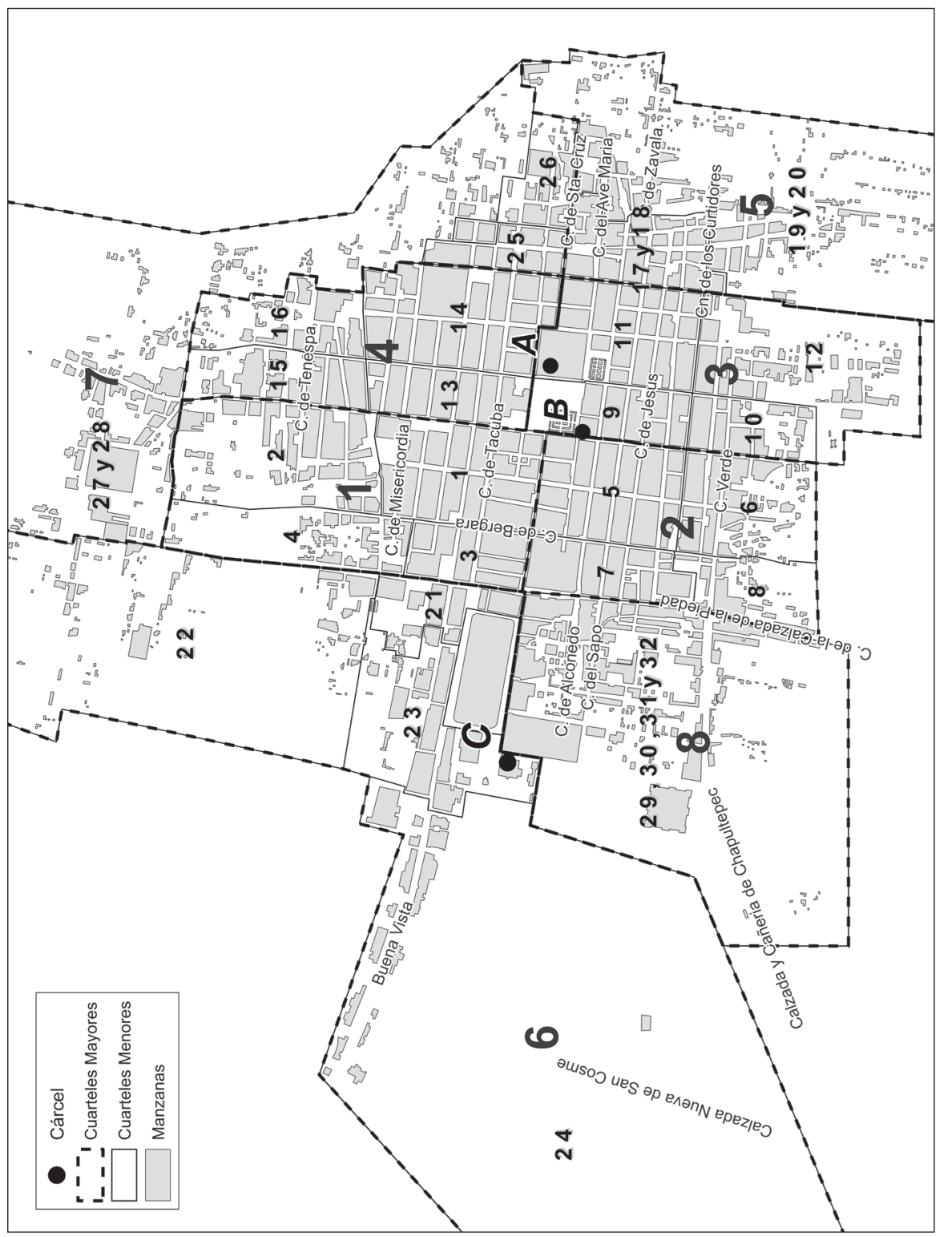

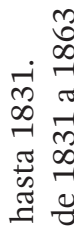

응 웅

2

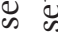

당

สี ซี

움

乙

웅

주

둥

듬

छ

䜦

艺

:

这.

$\sum \dot{ن}$

음

च

를

$\pi$

둥

o 0

\&

悹寻

+ن ซ

월 மे 
la detención panaderías, tocinerías y atolerías sirvieron como sitios improvisados e ilegales de aseguramiento, como solía denunciarse.

Dentro del microuniverso de agentes y cuerpos de seguridad y orden, probablemente los auxiliares de cuartel desempeñaron una relación mucho más estrecha con la justicia que el resto. No sólo representaron en un primer momento la opción de seguridad del Ayuntamiento, también encarnaron sus facultades judiciales frente a los juzgados de primera instancia y tribunales superiores ligados por excelencia al poder del Estado. La justicia del ayuntamiento se manifestó a través de los llamados alcaldes constitucionales que fungían como jueces sin formación en derecho y que llevaban a cabo conciliaciones y juicios verbales y también precisamente a través de los auxiliares de cuartel, quienes además de efectuar detenciones y remisiones a los juzgados, poseyeron una pequeña atribución judicial: podían efectuar juicios verbales.

Considerados como "los padres del vecindario", ellos podían "avenir, conciliar y pacificar las disensiones domésticas de que tengan noticia”, ${ }^{38}$ es decir, podían desempeñarse, según la Cartilla, como "jueces de paz" del cuartel, ${ }^{39}$ pero no podían realizar conciliaciones ni admitir demandas por ser atribución de los alcaldes constitucionales las primeras, y de los jueces letrados las segundas. Al tratar con los vecinos y sus discordias, en general, se les encargó actuar paternalmente, con moderación y prudencia, pudiendo dar aviso a los alcaldes constitucionales de mayor fuero judicial, cuando las riñas sobrepasaban su paternal paciencia.

Y en delitos de mayor proporción, prestaban sus servicios a la justicia letrada, en primera, segunda y hasta tercera instancias, por ejemplo, en homicidios, debían especificar en el parte que se entregaba en el juzgado de la cárcel la información correspondiente a los testigos presenciales - si es que los había- y las casas donde vivían, tomando nota de los pormenores de los delitos y todo cuanto "pudiera servir al juez en la sumaria”. ${ }^{40}$ En suma, los auxiliares actuaron como el gozne que unía las atribuciones judiciales del ayuntamiento y las del gobierno central, en la primera actuando como ejecutor y en las segundas como un instrumento al servicio de la justicia.

\footnotetext{
${ }^{38}$ AHDF, v. 390, "Cartilla para los auxiliares y ayudantes de cuartel”, art. 17.

${ }^{39}$ Ibidem, art. 9.

${ }^{40}$ Ibidem, art. 26.
} 
Cotidianamente, algunas otras de sus funciones consistieron en llamar al médico o al sacerdote allí donde riñas y golpes habían resultado en graves lesiones, o bien remitían al Hospital de San Andrés a los heridos y, si se trataba de alguien que mereciera ser conducido ante el juez, el auxiliar daba aviso a su regente para que el alcaide se hiciera cargo de los trámites correspondientes y se absorbieran los gastos que el detenido erogara.

Como las labores de los auxiliares eran demandantes, aun cuando contaban con ayudantes, una cédula ordenó que "todos los cuerpos de guardia disponibles" los ayudaran en sus deberes. La prensa reflejó la cooperación entre ellos; por ejemplo El Sol, en su sección "Policía de Seguridad", dio a conocer pequeños y muy interesantes reportes sobre la interacción entre los agentes del orden.

Uno de ellos, publicado el 6 de agosto de 1824, reseñó la jornada de la noche del 3 del mismo mes en que el auxiliar del cuartel menor número 31 fue socorrido por un guarda de alumbrado para conducir al cuartel de cívicos a un hombre que, armado de "sable y pistolas", estaba dando escándalo en la vía pública. ${ }^{41}$ La noche del 23 de julio del mismo año se capturó a dos hombres que llevaban dos extraños envoltorios. Según la nota de prensa, el guarda de alumbrado número 31 les mandó hacer alto, por lo que se dieron a la fuga dejando en la calle su botín, que consistía en 79 piezas de ropa. El auxiliar del cuartel número 7 llevó el bulto a su casa, ubicada en una panadería en calle de las Damas. ${ }^{42}$

Por supuesto que no todo marchó a la perfección y la cooperación entre ellos implicó un escenario no exento de discordias, como la suscitada el 19 de octubre de 1830 entre un ayudante de cuartel y un oficial. El primero, con la premura que la captura in fraganti de un reo ameritaba, solicitó ayuda al segundo, a lo que se negó, solicitándole la credencial que lo identificaba como ayudante de cuartel. Al negarse aquél a presentarla por saber del mal uso que solía hacerse de ella, el oficial le negó el auxilio. Tal actitud condujo al ayudante, llamado Ignacio López, a solicitar a su regidor de cuartel que elevara su queja al ayuntamiento, pues según él "no era la primera vez que se le negaba el auxilio aun yendo él en persona”. Y no sólo se corrió el riesgo de que el reo volviera a fugarse, sino también se puso en peligro él mismo; su reclamo tenía sobrada razón, en vista de que, como se recordará, a diferencia de los cuerpos de seguridad que dependían

41 "Policía de seguridad”, El Sol, 6 de agosto de 1824, p. 4.

42 “Policía de seguridad”, El Sol, 25 de julio de 1824, p. 4. 
del gobierno del Distrito, los auxiliares y sus ayudantes no percibían sueldo alguno. El cabildo respondió a la queja ordenando que se amonestara únicamente a los que negaron el socorro. ${ }^{43}$

Aunque en apariencia fue muy provechoso que los auxiliares vivieran en los cuarteles debido a que conocían, en mayor o menor medida a sus vecinos, algunas de sus costumbres y podían ubicar y reconocer las zonas más conflictivas o que merecían mayor atención, lo cierto fue que tanta cercanía actuó muchas veces en contra de la seguridad de los ciudadanos, como bien enuncia Serrano Ortega, abusando de su cargo concejil, algún auxiliar se había enriquecido, prolongando vejaciones y molestias de los vecinos; ${ }^{44}$ otros ni siquiera realizaban la detención de vagos, no perseguían a los ladrones y no obligaban a acatar los bandos de buen gobierno, como el que se refería a las pulquerías que no cerraban sus puertas después de las ocho de la noche. ${ }^{45}$

También les fueron adjudicadas arbitrariedades. En el bando fechado el 17 de abril de 1834 se daba cuenta de su cuestionable conducta; en él se señaló que algunos habían incurrido en detenciones arbitrarias de ciudadanos encerrándolos en lugares que no eran las cárceles y por tiempo que excedía el prevenido por las leyes. Según el artículo 151 de la Constitución de 1824 la detención no debía exceder de 60 horas, mientras que en el artículo 2, fracción II, de la primera ley centralista, la detención no debía ser mayor a tres días si la realizaba alguna autoridad política.

Otra denuncia común fue el cateo o allanamiento de casas, por lo que un bando publicado en 1834 se vio forzado a reivindicar la ley de 7 de febrero de 1822 en materia de justicia, en la que se estipuló que ningún alcalde auxiliar o ayudante podía allanar ni catear una casa sin previo mandato escrito de juez, ni realizar aprehensiones que no fueran in fraganti o en fuga de reo; en cualquier caso, la detención se efectuaría en la cárcel y no en sitio distinto a ésta, multando con 100 pesos a quien admitiera en su casa algún reo en calidad de detenido. Las detenciones debían informarse a algún alcalde constitucional durante las siguientes ocho horas,

43 AHDF, Auxiliares, v. 390, exp. 26, "Que les presten auxilio los militares a estos funcionarios", año 1830, f. 2 r.

${ }^{44}$ Serrano Ortega, "Los virreyes del barrio: alcaldes auxiliares y seguridad pública...", p. 31).

${ }^{45}$ Ibidem, p. 32. 
para que éste pudiera efectuar las diligencias necesarias, ${ }^{46}$ y así debía procederse aun cuando primero se hubiera presentado al reo al juez de turno. ${ }^{47}$

En los claroscuros de su desempeño, muy seguramente influyó que era un cargo honorífico, por tanto, sin goce de sueldo y no exento de riesgo, pues al ser civiles y no pertenecer a la corporación militar - como ocurría con aquellos adscritos en su mayoría al gobierno del Distrito Federal o a la Junta Departamental- carecían de la pericia debida. No por nada se pidió recurrir a las sanciones para quienes se negaran a recibir "el premio del tigre" que implicaba ser auxiliar.

Atajar delitos y delincuentes: oficiales auxiliares de policía, guardas diurnos y nocturnos

Probablemente, de los cuerpos de vigilancia más nutridos y que también tuvieron gran presencia en la ciudad (además de los auxiliares de cuartel) fueron los oficiales auxiliares de policía, pues según el bando de su creación (1834) se nombraría uno de ellos por cada manzana, por lo que en total hubo 245 y, como ya se dijo, bien podrían considerarse como el antecedente de la "policía judicial" en el sentido moderno, pues debían prestar sus servicios a los jueces de letras, si bien es verdad que los auxiliares de cuartel y el resto de agentes y cuerpos de seguridad poseían igual obligación, éstos tuvieron por misión, relevar a los auxiliares de cuartel cuando menos de las funciones judiciales en atención a que no podían velar por los asuntos de policía sin descuidar sus obligaciones de seguridad y vigilancia y viceversa. Así, los oficiales auxiliares se hicieron cargo de las necesidades de los jueces de letras: presentaban testigos, recababan pruebas del delito y todo lo necesario para instruir la sumaria. Para el desempeño de su labor, tuvieron la obligación de realizar un escrupuloso registro ciudadano en libros financiados por el Ayuntamiento.

En atención a los peligros que podían enfrentar, tanto a los oficiales auxiliares como a los ciudadanos o "cabezas de familia" que los socorrieran

${ }^{46}$ AHDF, Bandos, Leyes y Decretos, caja 6, exp. 77, "José María Tornel, gobernador del Distrito Federal. Restricciones para los alcaldes constitucionales al momento de aprehender a presuntos delincuentes", 17 de abril de 1834.

${ }^{47}$ AHDF, Bandos, Leyes y Decretos, caja 6, exp. 89, "El ciudadano José María Tornel, Gobernador del Distrito Federal. Las consignaciones de reos deben realizarlas los alcaldes auxiliares”, 28 de abril de 1834 . 
en la aprehensión de malhechores ${ }^{48}$ se les permitió disponer de un arma que no fuera de munición; así que tomando en cuenta que además cada oficial auxiliar designó a ocho vecinos de su manzana para hacer rondas, tenemos entonces una ciudad fuertemente vigilada... y legítimamente armada; según el plano 5 en que se representa su disposición territorial y los vecinos que los socorrían, prácticamente no habría un lugar sin vigilar.

En cada calle cuidaban "de la conservación del orden evitando pleitos, violencias y toda clase de insultos y tropelías", ${ }^{49}$ aprehendían in fraganti a los delincuentes. En los informes mensuales rendidos a los regidores de cuartel, debían asentar de cuanto vago y sospechoso tuvieran noticia y de cada delito y arresto efectuado en su manzana. ${ }^{50}$

Los oficiales auxiliares y los primeros cuatro vecinos comenzaban las rondas desde el inicio de las oraciones hasta la diez de la noche, mientras que los otros cuatro rondaban desde las cuatro a las seis de la mañana. Los individuos de la ronda no salían de su propia calle a no ser que fuera necesario. Para identificarse, pues no eran uniformados, llevaban una cédula impresa firmada por el auxiliar en la que se especificaba la calle de su ronda.

Durante el centralismo, el 22 de septiembre de 1841 se reivindicó la figura de los oficiales auxiliares por una razón de suma importancia. La ciudad de México se encontraba transitando por una convulsión social luego de que los primeros días de agosto de aquel año llegaran a la capital noticias de un nuevo pronunciamiento encabezado por el general Mariano Paredes y Arrillaga, jefe militar del estado de Jalisco, que se levantó en armas contra el presidente de la República, Anastasio Bustamante. ${ }^{51}$ María Gayón, quien reconstruyó los hechos vividos en la capital con motivo de tal pronunciamiento, encontró que los meses de agosto a diciembre de 1841, "la ciudad de México viviría días de guerra, hambre y angustia". Producto de las disputas políticas, la urbe fue escenario de luchas armadas, hasta que finalmente Antonio López de Santa Anna se hizo nuevamente del poder.

${ }^{48}$ AHDF, Bandos, Leyes y Decretos, caja 6, exp. 48, "José María Tornel, gobernador del Distrito Federal. Se nombrará un oficial auxiliar de policía en cada manzana, por los regidores encargados de los cuarteles en que está dividida la Ciudad para evitar la inseguridad que priva en ésta”, 4 de febrero de 1834, art. 2.

${ }^{49}$ Ibidem, art. 9.

${ }^{50}$ Ibidem, art. 17.

${ }^{51}$ María Gayón Córdova, “Guerra, dictadura y cobre. Crónica de una ciudad asediada (agosto-diciembre, 1841)", Historias. Revista de la Dirección de Estudios Históricos del INAH, n. 5,1984 , p. 53-65, p. 53. 


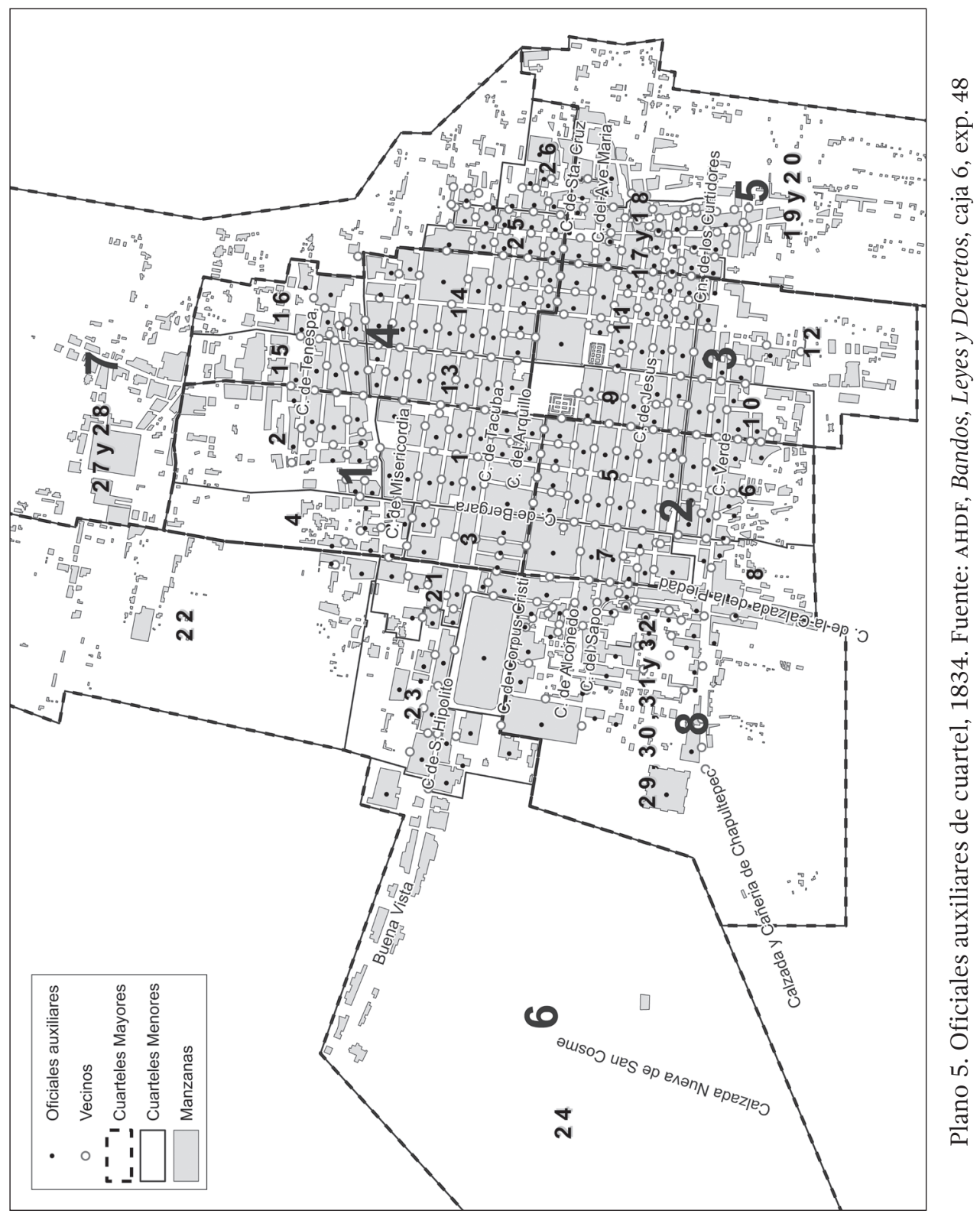


Fue a este célebre general a quien tocó hacer frente a una nueva crisis luego de que el levantamiento cesara: la devaluación de hasta un cincuenta por ciento de la moneda de cobre. La cosa no era para nada baladí, en tanto que dicha moneda se empleaba para pagar los salarios de los trabajadores (“empleados públicos, sirvientes, peones, jornaleros artesanos...") y debido a que los comerciantes se negaban a recibirla como pago válido en las transacciones más comunes y cotidianas, durante varios meses "se sucedieron tumultos, motines, asaltos a las panaderías, maicerías, tiendas de comestibles y talleres". ${ }^{2}$ En medio del caos, algunos agentes y cuerpos de seguridad asalariados - como fue el caso de los vigilantes de alumbrado y serenos- se negaron a prestar sus servicios a no ser que se les pagara en plata. ${ }^{53}$ De ahí la importancia de reforzar la vigilancia con aquellos que no percibían sueldo alguno, como los oficiales auxiliares de policía para los que se establecieron multas que consistieron en un pago mínimo de 10 pesos y máximo de 200, y a los ayudantes de mínimo un peso y máximo de 25 pesos o arresto proporcional, ${ }^{54}$ si se rehusaban a ocupar el cargo. Probablemente debido a su actuación, la ciudad pudo sobreponerse y no caer en niveles más alarmantes de crisis social, aunque sobre este punto, de momento, sólo caben las especulaciones.

Como iniciativa del prefecto de distrito para desplazar al ayuntamiento del ramo de seguridad pública, ${ }^{55}$ durante el centralismo, se puso en acción el cuerpo de policía municipal que se integró por vigilantes nocturnos y diurnos, una corporación asalariada, armada y uniformada, creada para "evitar toda clase de excesos, perseguir y aprehender a los delincuentes y conservar la tranquilidad pública”. ${ }^{56} \mathrm{El}$ destacamento de los nocturnos se integró por 114 individuos a caballo que obedecían a ocho cabos asignados cada uno a un cuartel mayor. Debido a que su Reglamento no mencionó el número ni la distribución de los vigilantes, pero suponiendo que ésta fuera

${ }^{52}$ Ibidem, p. 61.

${ }^{53}$ Idem.

${ }^{54}$ AHDF, Bandos, Leyes y Decretos, caja 11, exp. 37, "El ciudadano Francisco Ortiz de Zárate, ayudante general de la Plana mayor del ejército, General de brigada graduado y Gobernador interino del Departamento de México. Reglas para los oficiales de policía distribuidos en las manzanas de la capital”, 22 de septiembre de 1841, arts. 7-8.

55 Serrano Ortega, "Los virreyes del barrio: alcaldes auxiliares...", p. 53).

56 "Reglamento del cuerpo de policía municipal de vigilantes nocturnos", art. 9, 7 de abril de 1838, Dublán y Lozano, Legislación mexicana o colección completa de las disposiciones legislativas..., t. III. 
equitativa, podrían haber sido aproximadamente 14 caballeros por cuartel mayor bajo las órdenes de su respectivo cabo, y su distribución podría haber sido como se representa en el plano número 6.

Como se aprecia en el plano anterior, la distribución de los vigilantes y las facilidades de movilidad por el uso de caballos pudieron haber asegurado una cobertura mucho más amplia y eficaz, siendo uno de sus principales cometidos frente a la opción del ayuntamiento que encarnó en los auxiliares de cuartel y los oficiales auxiliares, su opción de vigilancia y seguridad más prolífica.

La faena de los vigilantes concluía a las 5:30 de la mañana los meses de marzo a agosto y hasta las 6:00 de la mañana de septiembre a enero. Detenían e inspeccionaban las cargas que circulaban por la ciudad, separaban "prudentemente a los que riñen antes de que se consume alguna desgracia”, prevenían y disolvían reuniones callejeras mayores a diez personas; detenían a todo sospechoso auxiliándose de los guardafaroleros para conducirlos a la cárcel. Se les aconsejó usar a discreción su arma para no enfrentar cargos ante la justicia (criminal ordinaria o militar, según fuera el caso).

Por su parte, el cuerpo de vigilantes diurnos se integró por 1 comandante, 5 cabos y 44 guardias que debían reunirse todos los días a las 6:00 de la mañana en el Portal de la Diputación. Salían de ahí a los sitios que les fueran asignados; cuatro rondines tendrían un lugar fijo mientras que uno de ellos sería "ambulante". Los cuatro rondines fijos y las zonas que abarcaron se pueden apreciar en el siguiente plano (zonas grises).

El rondín ambulante, el número uno, se integró con un jefe, un cabo y ocho hombres; recorría las zonas no contempladas por los rondines fijos; el resto de los rondines se integraron por un cabo y nueve guardias. ${ }^{57}$ Del plano anterior se desprende que los rondines no se organizaron tomando

${ }^{57}$ Las zonas de los rondines fijos se delimitaron de la siguiente manera: el rondín número dos recorría los trayectos comprendidos dentro del ángulo que formaban las calles de Santo Domingo a Santa Catarina Mártir, y de Tacuba a San Fernando, hasta la esquina llamada de Valdez. Al rondín tres tocó recorrer el área comprendida dentro del ángulo formado por las calles de Monterilla a Joya en adelante, y de la esquina de Profesa y San Francisco en adelante hasta la esquina de Plateros. Al rondín cuatro correspondieron las calles Flamencos y Rastro en adelante, y costado de Palacio y Acequia en adelante, cuyo vértice era la esquina de Palacio. A los del rondín cinco les competía el ángulo formado por las calles de Santa Teresa y Hospicio en adelante, y las del Relox en adelante, cuyo vértice quedaba en "la esquina de la botica llamada de Cervantes". 

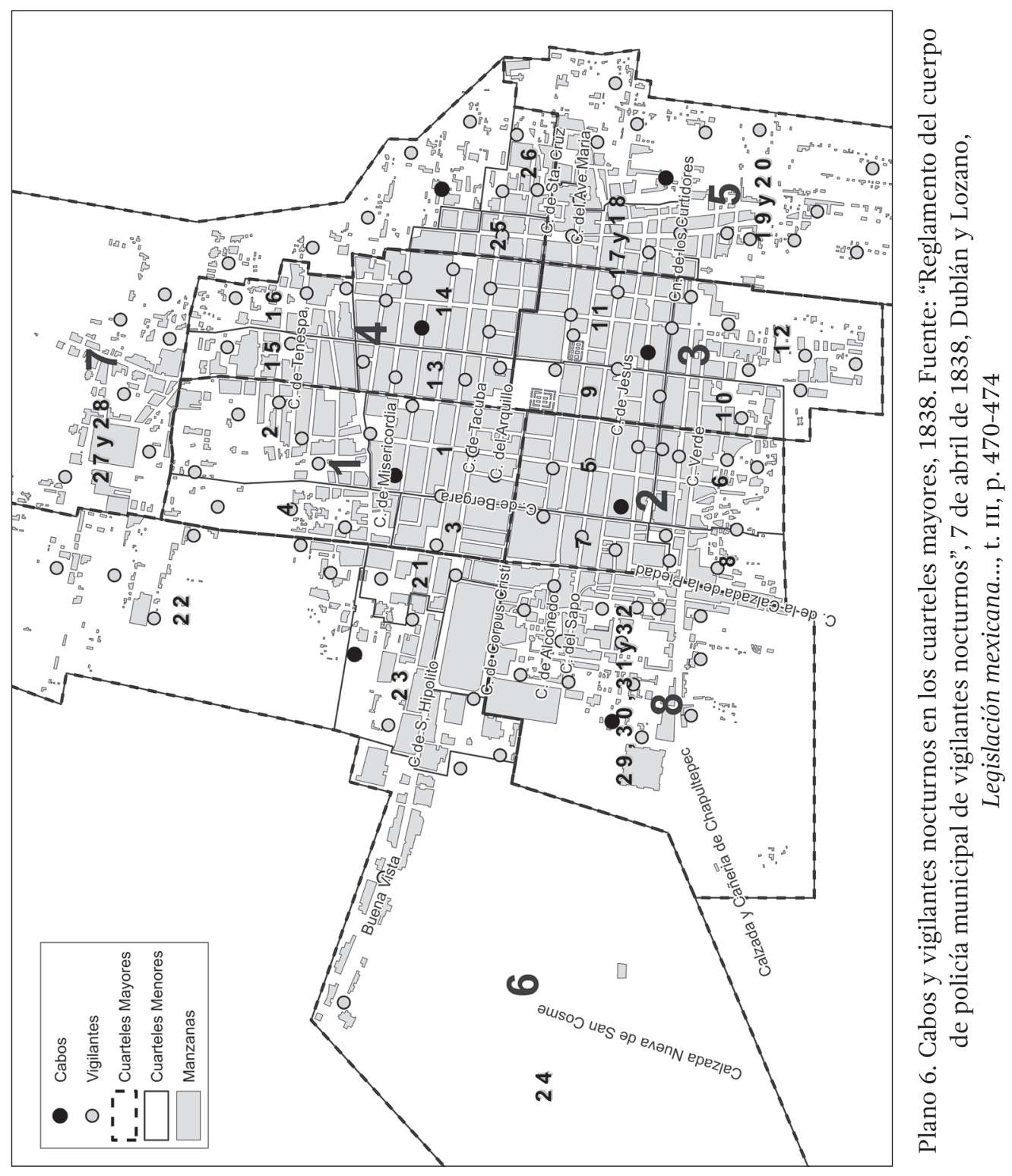


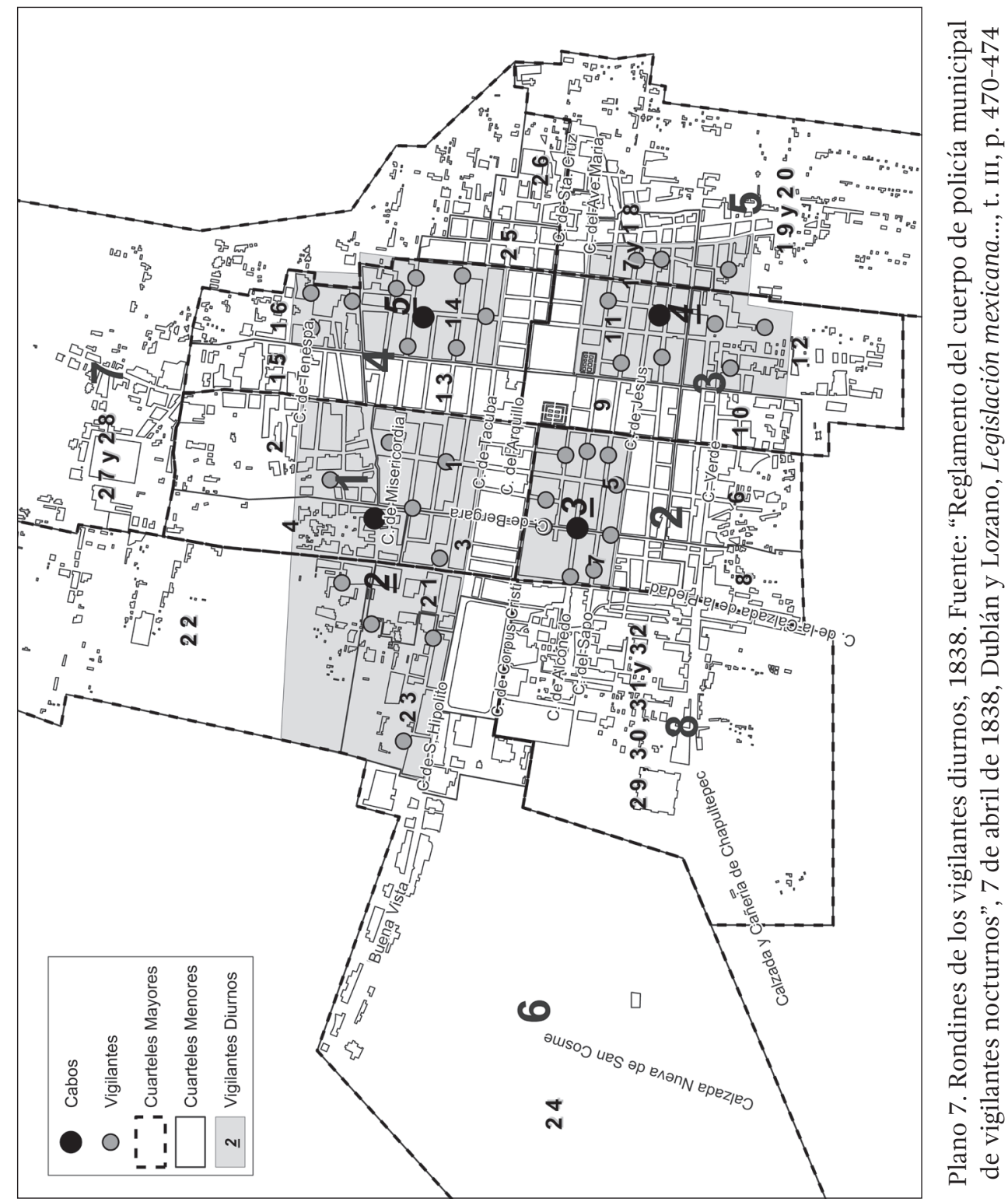


la división por cuarteles vigente, probablemente debido a que los auxiliares de cuartel estaban adscritos a ellos; más bien se procuró mantener cubierta la zona central de la ciudad, correspondiente a los cuatro primeros cuarteles mayores (y parte del 6), por ser la más poblada y con mayor actividad económica durante el día.

A los vigilantes diurnos también se les asignó velar por la policía de la ciudad, una función también desempeñada por el Ayuntamiento, por lo que vigilaban que se cumplieran los bandos correspondientes a la limpieza, cuidando que la basura no se arrojara en caños descubiertos, ni quedara en las calles al descargar la mercancía de las mulas y que luego éstas no permanecieran agolpadas en la calle y menos en la banqueta. ${ }^{58}$ Impedían que "comistrajos, dulces ni vendimias, asaduras, tripas, ni que nada de esto se venda por las calles sino precisamente en las plazas". 59

Obviamente, todo esto, según su Reglamento, ya que en la práctica, esos deberes si no se llevaron a efecto, difícilmente se cumplieron, según María Gayón, en la vigencia de la reglamentación urbana que databa de las últimas décadas del virreinato, que permite ver "que la insalubridad que se vivía en la ciudad no era por falta de reglamentos, sino por el incumplimiento de estos", ${ }^{60}$ debido a prácticas como "la corrupción de los encargados por aplicarlos", ${ }^{61}$ lo que no sólo afectó a ese importante ramo, también al de la seguridad pública. En cuanto a sus funciones de seguridad, éstas consistieron en las mismas que las de los nocturnos. ${ }^{62}$

La fuerza de policía de la ciudad instaurada en 1845 también alcanzó una importante presencia, pues se compuso de 140 elementos (100 a caballo y 40 pedestres). A diferencia de los anteriores, éstos sí usaban uniforme de color azul con la leyenda "policía" en la cinta del sombrero y hasta armas, pues varios de sus miembros poseían fuero militar. Las armas que podían emplear fueron sables, carabinas, cananas y municiones otorgadas por el gobierno. Lamentablemente no fue posible reconstruir carto-

${ }^{58}$ AHDF, Bandos, Leyes y Decretos, caja 9, exp. 60, "El ciudadano Luis Gonzaga Vieyra, Coronel retirado, y Gobernador constitucional del Departamento de México. Reglamento para los vigilantes diurnos", 7 de abril de 1838, art. 12, "Tercera".

${ }^{59}$ Ibidem, art. 12, "Quinta".

${ }^{60}$ Gayón Córdova, 1848. Una ciudad de grandes contrastes. I. La vivienda en el censo de población levantado durante la ocupación militar norteamericana, México, Instituto Nacional de Antropología e Historia, 2013, p. 88.

${ }^{61}$ Idem.

${ }^{62}$ Ibidem, art. 12, "Primera". 
gráficamente su radio de acción, sólo se sabe que el gobernador procuró que se distribuyeran "en cada punto cardinal de la ciudad". La consigna de su encargo, ya podrá preverse, consistió en "conservar el orden, cuidar de la seguridad pública y auxiliar la ejecución de los mandatos de las autoridades políticas y judiciales". ${ }^{63}$

Si la ciudad estuvo fuertemente custodiada como parecen sugerir los planos elaborados a partir de reglamentos y fuentes oficiales, entonces, $\dot{\iota}^{\mathrm{a}}$ qué se debió que pese a todos los empeños realizados tanto por el ayuntamiento de la ciudad y los gobiernos federal y centralista, las quejas sobre la inseguridad de la ciudad prosiguieran en semejantes términos prácticamente dos décadas después de alcanzada la independencia? Por ejemplo, según lo expuesto por Serrano Ortega, en 1822 un escritor anónimo se quejaba de que en la capital "se cometen porción de homicidios y robos, cuyas escandalosas perpetuaciones tienen compungidos los ánimos de sus habitantes; no se oyen por las plazas y calles otras voces que las de asesinaron y robaron. ${ }^{64}$

Hacia 1845, Francisco Ortiz Zárate, describió la inseguridad de la siguiente manera: "llegará y no muy tarde el caso de que tengamos cerrados de día nuestros hogares para custodiar nuestras propiedades y el reposo de nuestras familias, y que no podamos transitar las calles ni aún a la mitad del día sin ser asaltados". ${ }^{65}$ Obviamente, los planos sólo muestran el estado ideal de los servicios de seguridad asalariados y no asalariados en los que no están presentes las causas de sus deficiencias. Por ejemplo, fue muy común el ausentismo de los auxiliares de cuartel.

En 1829 José María Torices, regidor de los cuarteles 7 y $8,{ }^{66}$ elevó una sentida queja al gobernador del Distrito Federal, José María Tornel, denunciando que la noche del 21 de agosto de aquel año varios de los auxiliares de cuartel no se presentaron a sus respectivas rondas, faltando al debido "amor a sus habitantes", lo que había puesto a merced de los delincuentes casi a la ciudad entera, ya que fueron únicamente los auxiliares de los cuarteles mayores 1, 2 y 8 los que obedecieron el llamado del deber (véanse los

${ }^{63}$ AHDF, Bandos, Leyes y Decretos, caja 15, exp. 003, "Mucio Barquera, presidente de la Exma. Asamblea y Gobernador interino del Departamento de México. Decreto y reglamento para el Cuerpo de Policía”, 26 de septiembre de 1845, art. 12 del Decreto.

${ }^{64}$ Serrano Ortega, "Los virreyes del barrio: alcaldes auxiliares...”, p. 21.

${ }^{65}$ Idem.

${ }^{66}$ AHDF, Auxiliares, v. 390, exp. 24, "Lista de los auxiliares nombrados para el presente año en cabildo de 9 de enero; y de los Sres. Regidores respectivos”, 1829, f. 8, 9. 
planos 1 o 2 para dimensionar el tamaño del descuido). Falta de pago o de incentivos, peligros constantes, o simple indolencia pudieron haber influido en que los no asalariados desistieran de cumplir con su deber.

En el caso de las opciones asalariadas del gobierno y prefecto del Distrito, en épocas de crisis ya sociales o económicas podían, como en efecto hicieron durante la crisis de la moneda de cobre, negarse a prestar sus servicios sin el pago correspondiente. Pese a todo, con los vaivenes propios de una nave puesta a merced de la tempestad, la ciudad se mantuvo viva y los aparatos de justicia en funciones, no de forma eximia, claro está, pero sí suficiente.

De los detenidos y la justicia

¿Qué pasaba una vez que los agentes y cuerpos de seguridad, venciendo la suspicacia de su actuación y cumpliendo con su deber, lograban consignar a alguien a la cárcel? Como se mencionó, cuando una persona era detenida por delito presunto o comprobado, se le remitía a la cárcel, usualmente a la de la Diputación o Ciudad ubicada en el cuartel mayor 3, menor 9; o cuando el caso lo ameritaba, a la Cárcel Nacional, pues ahí había un juzgado atendido por un juez letrado de turno.

Los delitos más comunes en una noche de rondas y patrullas estribaban en golpes, riñas, heridas, robos o lances perpetrados por gente con actitud sospechosa. Los pormenores de la remisión debían ser consignados por el agente que la realizaba - por lo que, de preferencia, debían saber leer y escribir-, anotando el nombre del reo, la razón y las circunstancias de su detención, presentando, además, de ser el caso, el arma agresora para el mejor entendimiento del médico y el juez. Ahí concluía la labor de los vigilantes citadinos, a no ser que el juez requiriera mayor testimonio sobre las circunstancias del delito, en cuyo caso podía solicitar nuevamente el auxilio de aquéllos, ya para rendir ellos mismos testimonio de lo visto, conducir testigos del hecho, recabar pruebas del delito y cuanto el juez indicara. En general los vigilantes terminaban asumiendo funciones de policía en sentido moderno, no sólo de "seguridad" sino incluso especializada, "judicial".

Los expedientes que contienen la hoja de remisión al juzgado muestran pasajes interesantes que condensan el fin de la vigilancia: no sólo el orden, sino el principio de la justicia. Así, por ejemplo, el 16 de agosto de 1844 el 
auxiliar del cuartel menor número 6 remitió a la cárcel de Diputación o Ciudad, a disposición del juez, a Anselmo Navarrete e Isidro Asencio por haberle "roto la cabeza" al primero con un serrote que, según el parte expedido, envió junto con los revoltosos. Ya en el juzgado, el médico de la cárcel inspeccionaba las heridas, luego de lo cual expedía un certificado; en este caso se mencionó que Navarrete estaba ya sano de la herida que le fue atendida en la enfermería de la cárcel. En vista de que no hubo complicaciones médicas que lamentar, el juez (cuyo nombre no se consignó) ordenó que Navarrete fuera dejado en libertad por compurgado y que el heridor Asencio sufriera ocho días de servicio de cárcel. ${ }^{67}$

Otra remisión a la cárcel de Ciudad la efectuó el auxiliar del cuartel menor 1, el 29 de agosto de 1844, por el delito de golpes al encontrar a tres hombres ensañándose con otro. José María Cadena recibió "muchos azotes" en el cuerpo propinados por Tomás Maldonado, Manuel Rodríguez y algún otro que no se pudo aprehender. Tal como lo marcaba el protocolo, el auxiliar actuó con prudencia y buen juicio, por lo que envió lo antes posible al herido al Hospital de San Andrés, pues el certificado médico fue expedido en la misma fecha que la remisión a la cárcel de los dos presuntos culpables. En dicho documento el médico expresó que las contusiones eran de "primer grado" y las clasificó de ligeras. Aproximadamente dos semanas después, el 13 de septiembre, el juez de turno de la Cárcel de Ciudad sentenció a Rodríguez a una multa de 30 pesos y dos meses de servicio de cárcel desde la fecha de su prisión; por su parte Maldonado tuvo que pagar 20 pesos de multa y purgar un mes de servicio de cárcel; el herido recibiría la mitad de cada multa como indemnización y la otra parte se destinó a pagar las costas de la escribanía. ${ }^{68}$

En otro caso, fechado el 5 de junio de 1844, el guarda mayor Pomposo Gómez envió a la Cárcel de Ciudad a un par de personas que capturó el guarda número once. Los dos reos, José María Ángeles y Zenobia Eslava, quedaron consignados por riña y heridas. El mismo día fueron inspeccionados por el médico José María Maldonado, quien asentó en su certificado que Zenobia tenía una mordida en la punta de la nariz que interesó los tegumentos y el cartílago y que estaba muy inflamada, además de una laceración en el cuello que clasificó como leve, no así la de la nariz que

${ }^{67}$ Archivo General de la Nación, Tribunal Superior de Justicia del Distrito Federal (en adelante, AGN, TSJDF), caja 5, 1844, exp. 844.

${ }^{68}$ AGN, TSJDF, caja 5, 1844, exp. 237. 
consideró "no carecer de peligro por accidentes", es decir, que mal curada podía representar un riesgo para la presa. Por fortuna no fue el caso y la sentencia emitida por el juez de turno, varios días después, el 19 de junio, puso en libertad a ambos, por compurgados y "seriamente apercibidos" para que, en lo sucesivo, guardaran el debido comportamiento. ${ }^{69}$

En términos generales los reos detenidos por rondas y patrullas que se remitían a la cárcel solían ser debido a delitos menudos (lo que no excluye, obviamente, a los de mayor cuantía, escándalo y gravedad). Ese tipo de delitos se seguían de oficio y por lo general implicaban sentencias "livianas" en un juicio sumario, es decir, por ofensas menores y solían comprender la mayoría de los juicios en la capital; según Michael Scardaville, a principios del siglo XIX, éstos comprendían hasta el 92\% de los enjuiciados. ${ }^{70}$ Dicho porcentaje, de corroborarse para el periodo de las dos repúblicas, mostraría la importancia que los cuerpos y agentes de seguridad tuvieron para la ciudad, pues fueron ellos los que efectuaron buena parte de las remisiones al juzgado carcelario, principalmente al de la Diputación. Sobre este punto, cabe aclarar que no fueron la única vía para llegar a los juzgados ni los carcelarios fueron los únicos. La doctrina vigente estableció tres vías: la acusación, la denuncia y la pesquisa, ${ }^{71} \mathrm{y}$ éstos eran frecuentes en los juzgados de letras capitalinos (hubo seis de ellos durante la primera república federal y cinco en la centralista) y que solían proceder a pedimento de parte. Por supuesto los procesos de carácter ordinario seguidos en aquéllos serán parte de otro estudio, pues su importancia también es vital para comprender, en su conjunto, el funcionamiento de las instituciones judiciales.

${ }^{69}$ AGN, TSJDF, caja 5, 1844, exp. 710.

${ }^{70}$ Michael C. Scardaville, "Los procesos judiciales y la autoridad del Estado: reflexiones en torno a la administración de la justicia criminal y la legitimidad en la ciudad de México, desde finales de la Colonia hasta principios del México independiente", en Brian F. Connaughton (coord.), Poder y legitimidad en el México del siglo XIX. Instituciones y cultura política, México, Universidad Autónoma Metropolitana-Iztapalapa/Miguel Ángel Porrúa/ Consejo Nacional de Ciencia y Tecnología, 2003, p. 379-428, p. 389-390.

${ }^{71}$ Anastasio de la Pascua (ed.), Febrero mejicano, o sea la librería de los jueces, abogados y escribanos que refundida, ordenada bajo nuevo método, adicionada con varios tratados y con el título de Febrero novísimo; dio a la luz D. Eugenio de Tapia: nuevamente adicionada con otros diversos tratados, y las disposiciones del derecho de Indias y del patrio, México, Imprenta de Galván a cargo de Mariano Arévalo, 1835, v. viI, p. 184, 190, 192. 
Reflexiones finales

La división de la capital con la Ordenanza de 1782 tuvo una función muy clara: facilitar los tractos de la justicia. Una ciudad ordenada podía favorecer su necesaria vigilancia. Del orden urbano se dio paso a la creación de diversos agentes de seguridad y vigilancia y en buena medida utilizaron la traza urbana para planear sus rondas y patrullas. Los planos de la capital en los que se ha reconstruido o representado la distribución de los vigilantes resultan muy claros al respecto y, de hecho, dimensionan hipotéticamente la magnitud y los alcances de su vigilancia. Así que, cuando menos en teoría, se trató de una capital fuertemente custodiada, pues en la práctica no siempre los agentes del orden (asalariados o no) se sintieron comprometidos con el desempeño de su encargo, el que era sumamente demandante y peligroso.

Algunos agentes y cuerpos de seguridad se disolvieron al relevo político, otros se mantuvieron pese a él, como los que dependieron del ayuntamiento de la ciudad: tal fue el caso de los regidores y auxiliares de cuartel y los oficiales auxiliares de policía. Los primeros surgieron durante la administración de Iturbide, aunque sus raíces son novohispanas y los otros, a finales del primer federalismo, manteniéndose ambos vigentes durante el centralismo.

Entre los vigilantes hubo una organización más o menos compleja, derivada de su origen. Aquellos creados y dependientes del gobierno del Distrito Federal o de la Junta Departamental durante el centralismo solían mostrar estructuras organizativas mucho más complejas: por lo general, utilizaban armas, sables o pistolas, concentraban a las patrullas a caballo, eran asalariados y utilizaban uniforme para su debida distinción. Entre ellos encontramos a los responsables del alumbrado de las calles y celadores públicos, a la fuerza de policía y al cuerpo de policía municipal, integrado por civiles y, según los documentos de su creación, varios de sus individuos poseían fuero militar y podían ser juzgados en sus respectivos tribunales si cometían algún delito fuera o dentro del desempeño de su labor.

En cuanto a los que dependieron del Ayuntamiento, se encuentran principalmente los auxiliares de cuartel y oficiales auxiliares que no usaban uniforme, no eran asalariados y utilizaban a los ciudadanos como su pilar operativo, algo muy conveniente pues, al ser vecinos de los lugares que custodiaban, contaban con un mejor conocimiento de sus paisanos, hábitos y costumbres, así como de los sitios y lugarejos que debían vigilar con 
mayor escrúpulo. Ello les otorgó enormes ventajas sobre la policía montada y demás destacamentos asalariados, externos o ajenos a los lugares que vigilaban, aunque paradójicamente tal conocimiento favoreció prácticas ilegales y abusos.

Aunque no eran asalariados y solían descuidar sus labores y no presentarse a las rondas debidas, en tiempos de crisis, como la del cobre, al fallar las corporaciones pagadas que no percibían un sueldo adecuado, las honoríficas pudieron ser la mejor opción para mantener a la capital y sus ciudadanos bajo control.

Todos los agentes y cuerpos de seguridad que se han explorado aquí tuvieron por misión primordial vigilar, perseguir, aprehender y conducir a la cárcel a hombres y mujeres que alteraban el orden público, y lejos de lo que puede creerse, sólo dos de ellos se ocuparon de labores de policía de manera expresa: los alcaldes auxiliares de cuartel y los vigilantes diurnos pertenecientes al cuerpo de la policía municipal del centralismo. Estos últimos, dependientes de la Junta Departamental, complementaban a los alcaldes auxiliares, cuando menos sólo de día y en los cuarteles más céntricos, concurridos y por tanto que suscitaban mayor interés en las autoridades (véase plano 6).

Por otro lado, los cuerpos y agentes de seguridad interactuaban entre ellos, lo que ayudó a subsanar la ausencia de algunos o la falta de pericia y responsabilidad de otros. Algunas veces disuadían paternal y amistosamente a los escandalosos, o por las armas cuando la situación lo ameritaba. Aunque en general las detenciones se lograban cumpliendo las expectativas de formalidad debidas, no estuvieron exentas de abusos, arbitrariedades y hasta corruptelas. Sin embargo, sorteados los inconvenientes y las críticas, lograron alimentar al gran lobo de la justicia que abría sus fauces diariamente, a todas horas, en el juzgado carcelario. Escandalosos, ebrios, vagos, mal entretenidos, heridores, rateros, ladrones y hasta homicidas llenaron el largo tracto de la justicia cotidiana. Cuando los delitos eran menudos el juez mandaba poner en libertad a los reos a los pocos días; otras veces, por la gravedad, se mandaba instruir la sumaria y dar inicio a un cansino proceso judicial. Así, la vigilancia de la ciudad se constituyó en el motor de la justicia cuando menos en su forma más prolífica. 


\section{FUENTES}

Archivos

Archivo Histórico del Distrito Federal (AHDF)

Fondo: Ayuntamiento Gobierno del Distrito Federal

Ramos: Auxiliares; Bandos, Leyes y Decretos; Demarcaciones: Cuarteles; Ordenanzas y Otros Documentos.

Archivo General de la Nación (AGN)

Sección: Tribunal Superior de Justicia del Distrito Federal

\section{Hemeroteca}

Hemeroteca Nacional Digital de México (HNDM)

Prensa:

El Sol, 1824, 1825.

El Mosquito Mexicano, 1837.

\section{Mapoteca}

"Manuel Orozco y Berra"

Plano:

García Conde, Diego, Plano general de la Ciudad de México. Levantado por el Teniente Coronel Don Diego García Conde en el año de 1793. Aumentado y corregido en lo más notable por el Teniente Coronel retirado, Don Rafael María Calvo en el de 1830, 1830.

\section{Leyes}

Acta Constitutiva de la Federación Mexicana, 31 de enero de 1824.

Constitución Federal de los Estados Unidos Mexicanos. Sancionada por el Congreso general constituyente, el 4 de octubre de 1824.

Siete Leyes Constitucionales (1836). 
Referencias

Arrillaga, Basilio José, Recopilación de leyes, decretos, bandos, reglamentos, circulares y providencias de los supremos poderes y otras autoridades de la República Mexicana formada por orden del supremo Gobierno, México, Imprenta de J. M. Fernández de Lara, calle de la Palma núm. 4, 1838.

Dublán, Manuel, y José María Lozano, Legislación mexicana o colección completa de las disposiciones legislativas expedidas desde la independencia de la República ordenada por los licenciados Manuel Dublán y José María Lozano, México, Imprenta del Comercio, a cargo de Dublán y Lozano, Hijos, Calle de Cordobanes, número 8,1876 , t. III.

Exbalin Oberto, Arnaud, "Los alcaldes de barrio. Panorama de los agentes del orden público en la ciudad de México a finales del siglo xvin", Antropología. Boletín Oficial del Instituto Nacional de Antropología e Historia, México, n. 94, 2012, p. 49-59.

Gayón Córdova, María, "Guerra, dictadura y cobre. Crónica de una ciudad asediada (agosto-diciembre, 1841)”, Historias. Revista de la Dirección de Estudios Históricos del INAH, n. 5, 1984, p. 53-65.

1848. Una ciudad de grandes contrastes. I. La vivienda en el censo de población levantado durante la ocupación militar norteamericana, México, Instituto Nacional de Antropología e Historia, 2013.

Gortari Rabiela, Hira de, "La ciudad de México de finales del siglo xviII: un diagnóstico de la 'ciencia de policía' ”, Historia Contemporánea, n. 24, 2002, p. 115-135.

Hernández Franyuti, Regina, "Historia y significados de la palabra policía en el quehacer político de la ciudad de México. Siglos Xvi-XIX”, Ulúa. Revista de historia, sociedad y cultura, n. 5, 2005, p. 9-34.

El Distrito Federal: historia y vicisitudes de una invención, 1824-1994, México, Instituto de Investigaciones Dr. José María Luis Mora, 2008 (Historia Urbana y Regional).

Huertas VÁzquez, Eduardo, “Los majos madrileños y sus barrios en el teatro popular”, en Javier Huerta Calvo y Emilio Palacio Fernández (coords.), Al margen de la Ilustración: cultura popular, arte y literatura en la España del siglo XVIII, Ámsterdam, Rodopi, 1998, p. 117-143.

MARIn, Brigitte, "Los alcaldes de barrio en Madrid y otras ciudades de España en el siglo XVIII: funciones de policía y territoriales”, Antropología. Boletín oficial del Instituto Nacional de Antropología e Historia, n. 94, 2012, p. 19-31.

MALvido, Elsa, La población, siglos XVI al XX, México, Universidad Nacional Autónoma de México/Océano, 2006. 
NACIF Mina, Jorge, "Policía y seguridad pública en la ciudad de México, 1770-1848”, en Regina Hernández Franyuti (comp.), La ciudad de México en la primera mitad del siglo XIX, 2 v., México, Instituto de Investigaciones Dr. José María Luis Mora, 1994, v. II, p. 9-50.

Pascua, Anastasio de la (ed.). Febrero mejicano, o sea la librería de los jueces, abogados y escribanos que refundida, ordenada bajo nuevo método, adicionada con varios tratados y con el título de Febrero novísimo; dio a la luz D. Eugenio de Tapia: nuevamente adicionada con otros diversos tratados, y las disposiciones del derecho de Indias y del patrio, México, Imprenta de Galván a cargo de Mariano Arévalo, 1835, v. VII.

Pérez Toledo, Sonia, Población y estructura social en la ciudad de México, 1790-1842, México, Universidad Autónoma Metropolitana-Iztapalapa, 2004.

Pulido Esteva, Diego, "Policía: del buen gobierno a la seguridad, 1750-1850", Historia Mexicana, n. 3, enero-marzo 2011, p. 1595-1642.

Rodríguez De SAN Miguel, Juan, Manual de providencias económico-políticas para uso de los habitantes del Distrito Federal, México, Imprenta de Galván a cargo de Mariano Arévalo, 1834.

Pandectas hispano-megicanas, o sea, Código general comprensivo de las leyes generales, útiles y vivas de las Siete Partidas, recopilación novísima, la de Indias, autos y providencias conocidas por de Montemayor y Belaña, y cédulas posteriores hasta el año de 1820: con exclusión de las totalmente inútiles, de las repetidas, y de las expresamente derogadas, 3 v., México, Impreso en la Oficina de Mariano Galván Rivera, 1839, v. I y III.

ScArdaville, Michael C., "Los procesos judiciales y la autoridad del Estado: reflexiones en torno a la administración de la justicia criminal y la legitimidad en la ciudad de México, desde finales de la Colonia hasta principios del México independiente", en Brian F. Connaughton (coord.), Poder y legitimidad en el México del siglo XIX. Instituciones y cultura política, México, Universidad Autónoma Metropolitana-Iztapalapa/Miguel Ángel Porrúa/Consejo Nacional de Ciencia y Tecnología, 2003, p. 379-428.

Serrano Ortega, José Antonio, "Los virreyes del barrio: alcaldes auxiliares y seguridad pública, 1820-1840”, en Carlos Illades y Ariel Rodríguez Kuri (eds.), Instituciones y ciudad. Ocho estudios históricos sobre la ciudad de México, México, Sociedad Nacional de Estudios Regionales/Uníos, 2000, p. 21-60.

Torre Villalpando, Guadalupe de la, "La demarcación de cuarteles. Establecimiento de una nueva jurisdicción en la ciudad de México del siglo xviı", en Sonia Lombardo de Ruiz (coord.), El impacto de las reformas borbónicas en la estructura de las ciudades, un enfoque comparativo: Memoria del I Simposio Internacional sobre Historia del Centro Histórico de la Ciudad de México, México, 
Gobierno de la Ciudad de México/Consejo del Centro Histórico de la Ciudad de México, 2000, p. 89-108.

Vázquez Alfaro, José Luis, Distrito Federal. Historia de las instituciones jurídicas, México, Universidad Nacional Autónoma de México, Instituto de Investigaciones Jurídicas/Senado de la República, 2010.

YÁñez Romero, José Antonio, Policía mexicana: cultura política, (in)seguridad y orden público en el gobierno del Distrito Federal, 1821-1876, México, Universidad Autónoma Metropolitana/Plaza y Valdés, 1999. 